\title{
Geophysical surveys integrated with rainfall data analysis for the study of soil piping phenomena occurred in a densely urbanized area in eastern Sicily
}

\author{
Graziano Patti $^{1}$ - Sabrina Grassi ${ }^{1}$ - Gabriele Morreale ${ }^{2}$. Mauro Corrao ${ }^{2}$. \\ Sebastiano Imposa ${ }^{1}$
}

Received: 2 November 2020 / Accepted: 4 May 2021 / Published online: 13 May 2021

(C) The Author(s) 2021

\begin{abstract}
The occurrence of strong and abrupt rainfall, together with a wrong land use planning and an uncontrolled urban development, can constitute a risk for infrastructure and population. The water flow in the subsoil, under certain conditions, may cause underground cavities formation. This phenomena known as soil piping can evolve and generate the surface collapse. It is clear that such phenomena in densely urbanized areas represent an unpredictable and consistent risk factor, which can interfere with social activities. In this study a multidisciplinary approach aimed to obtain useful information for the mitigation of the risks associated with the occurrence of soil piping phenomena in urban areas has been developed. This approach is aimed at defining the causes of sudden soil subsidence events, as well as the definition of the extension and possible evolution of these instability areas. The information obtained from rainfall data analysis, together with a study of the morphological, geological and hydrogeological characteristics, have allowed us to evaluate the causes that have led to the formation of soil pipes. Furthermore, performance of 3D electrical resistivity surveys in the area affected by the instability have allowed us to estimate their extension in the subsoil and identifying the presence of further areas susceptible to instability.
\end{abstract}

Keywords Rainfall data analysis · 3D Electrical resistivity tomography $\cdot$ Soil piping · Hazard $\cdot$ Mt. Etna south-eastern flank

Sabrina Grassi

sgrassi@unict.it

1 Department of Biological, Geological and Environmental Sciences, Earth Science Section, University of Catania, Corso Italia, 57, 95129 Catania, Italy

2 Geocheck Srl, Aci Sant Antonio, Via Stazzone, 45, 95025 Catania, Italy 


\section{Introduction}

The devastating natural events that have affected the entire Italian peninsula in recent decades have strongly highlighted how the physical vulnerability of the territories increases exponentially due to the urban and infrastructural expansion. This uncontrolled urban growth involves, after the occurrence of natural phenomena, such as seismic events, landslides, floods, etc., infrastructure damage and loss of human lives.

A phenomenon that constitutes a real civil protection problem, especially if it occurs in an urban environment, is represented by soil piping.

The term soil piping indicates erosion phenomena that lead to the occurrence of land subsidence. It is defined as the hydraulic removal of underground soil that causes the underground channels and cavities formation (Boucher 1995), which can cause the collapse of the soil surface layer.

This phenomenon, which can have both natural and anthropic origin, depends on various factors such as the lithological and structural nature of the subsoil, the waterproof urban surface connected with the hydrography characteristics, the increasing "urbanization" of the subsoil (undergrounds and tram lines, underground utilities, drainage system, etc.), the weather phenomena, the subsoil hydrogeological nature and its interaction with the mentioned factors (Waltham et al. 2005; Kaufmann 2014; Vannoppen et al. 2017; Bernatek-Jakiel and Poesen 2018; Bovi et al. 2020).

In most cases, the water is the triggering agent, acting both from the physical-mechanical and chemical point of view and consequently favouring the soil subsidence (Zeng et al. 2016). Obviously, what has been said denotes a significant problem for the urban security and for the ordinary social activity in these contexts (Intrieri et al. 2015; Sevil et al. 2017).

The knowledge of these phenomena, from the triggering factor to their occurrence, is certainly essential to prevent collapses episodes or take action and manage emergency situations after the subsidence development.

To better understand and avoid these events is essential a deep knowledge of the subsoil features, which is achievable with the execution of mechanical drillings boreholes, geotechnical investigations and geophysical surveys. Some of the mentioned subsoil investigations are significantly time spending and invasive, making them not easily applicable during the daily activities that can take place in urban areas.

Geophysical surveys can overtake these problems and provide the opportunity to evaluate fundamentals geotechnical parameters of the subsoil and their variation in space and time, constantly screening the subsoil conditions (Zhou et al. 2002; Barone et al. 2004; Imposa et al. 2004, 2007; Krawczyk et al. 2012; Samyn et al. 2014; Giampaolo et al. 2016; Bernatek-Jakiel and Kondracka 2016; Lee et al. 2016; Sevil et al. 2017; Bernatek-Jakiel and Poesen 2018).

In detail, the use of different geophysical methodologies allow to define accurately the subsoil stratigraphy, the variation of the elastic parameters related with the nature of lithotypes, the site hydrogeology, the presence of cavities, structures, etc. (Samyn et al. 2014; Pazzi et al. 2016, 2018; Pappalardo et al. 2018; Carollo et al. 2020). Furthermore, accompanying geophysical data with rainfall data it is possible to obtain more realistic and precise models, which take into account the water circulation, which can be at the surface or underground.

In this study, the results of geophysical, geological, hydrogeological and rainfall datasets will be analysed, to understand the trigger factors associated with some 
collapses events occurred between 2015 and 2017 in the downtown of Valverde, eastern Sicily. Moreover, the goal of this study is also to evaluate the volume of the weak surface soil which can subside in future events of intense rain.

\section{Geologic and hydrogeologic settings}

The Valverde municipality is situated, at $305 \mathrm{~m}$ a. s. 1., in the eastern Sicily on the southeast flank of Mt. Etna. As shown in Fig. 1a, b, the town is settled in the Settepani torrent catchment area. This stream has an irregular and seasonal behaviour, associated with the extent and the strength of the rain events which can vary during the year. This is a typical
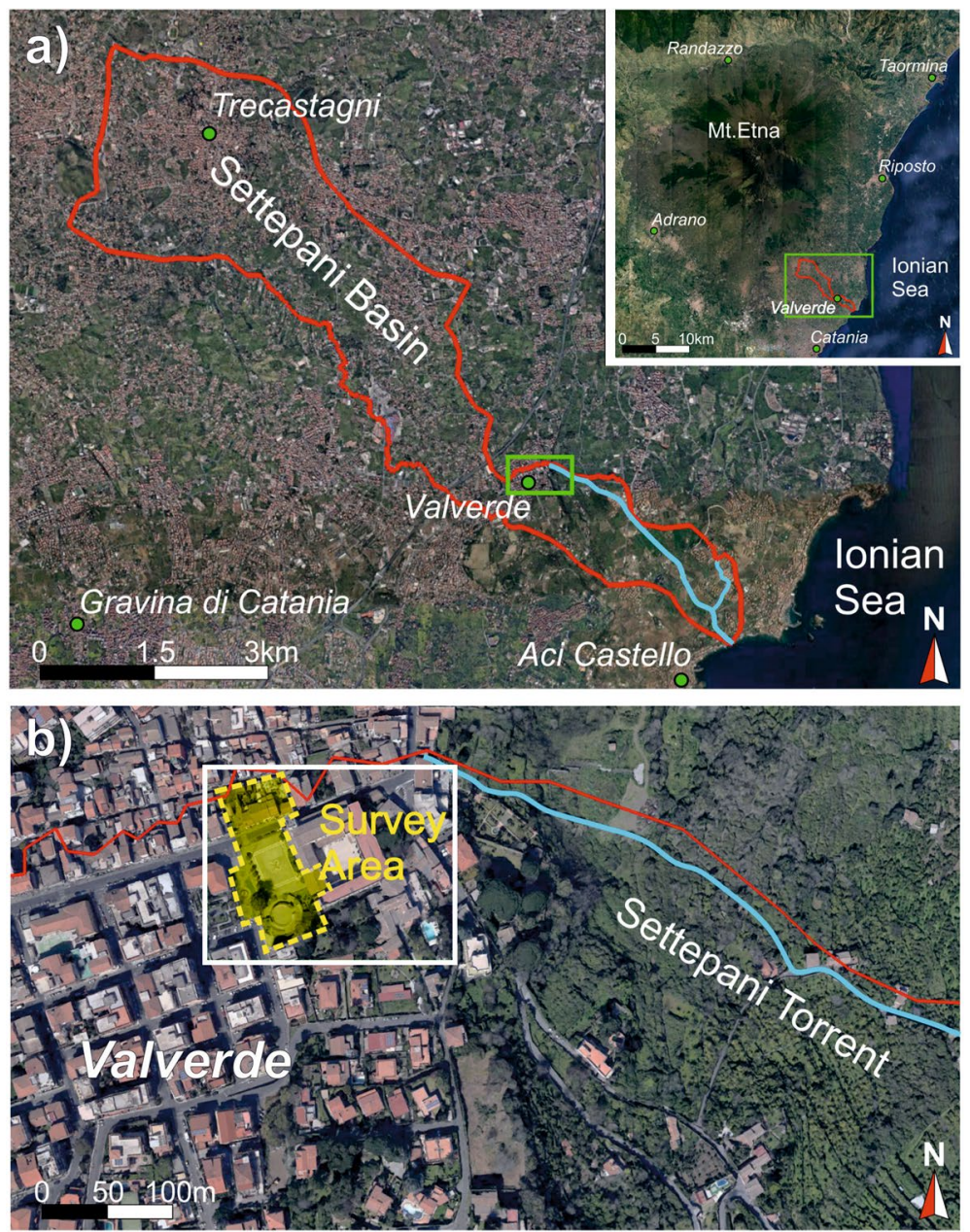

Fig. 1 a Location of Settepani basin, the red line point out the shape of hydrographic basin, the light blue line show the development of hydrographic network; inset upper right shows the location of Valverde municipality in the south-eastern flank of Mt. Etna; b position of survey area respect to Settepani torrent 
feature, related with the short overflow time of the etnean torrents, during the rainy months intense and short floods can occur (Ferrara and Pappalardo 2008; Costantini et al. 2013; Caccamo et al. 2017).

From the morphological point of view, the Settepani torrent has a surface area of $14.2 \mathrm{~km}^{2}$ which gradually slopes from 640 to $0 \mathrm{~m}$ a. $\mathrm{s}$. 1. Its maximum axis direction is east-southeast and it has a not well-developed hydrographic network, as can be seen from Fig. 1. This is due to the presence, especially in the western part of the catchment area, of high permeability volcanic rocks outcrops and associated groundwater flow (Romano et al. 1979; Ferrara and Pappalardo 2008). The main part of the network is $4.6 \mathrm{~km}$ in length and it starts few hundred metres north-east from the historical centre of Valverde. Before joining the sea this main axis collects water from a smaller affluent stream. Analyzing the lithotypes of the area it is possible to suppose that the historical centre of Valverde is developed on a paleo-riverbed (Fig. 1b).

From the geological perspective (Fig. 2a, b), the catchment area of the torrent is mainly characterized by lava flows and pyroclastic fall out deposits, localized in the western side.
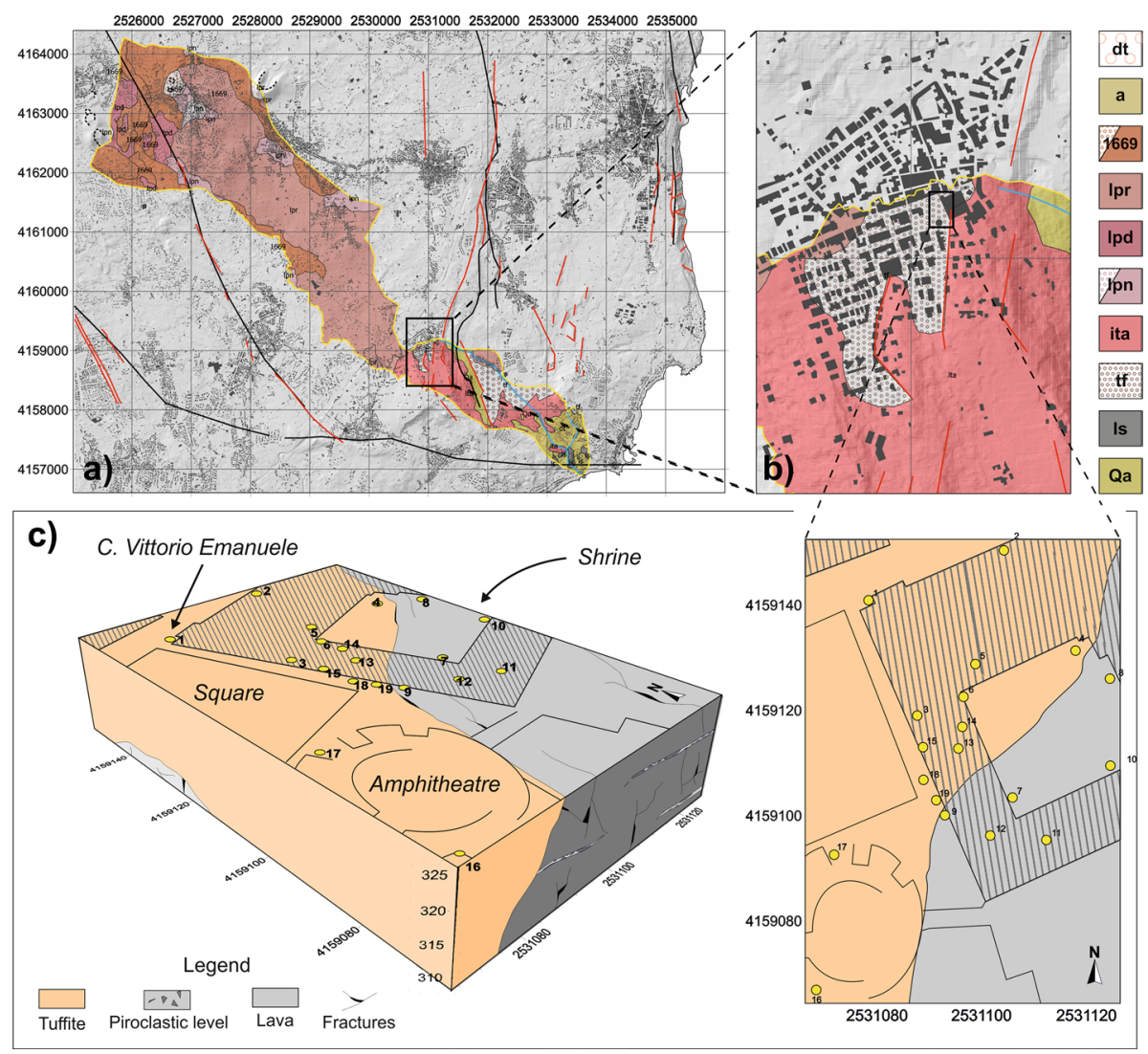

Fig. 2 a, b Geological map of Settepani Basin: dt debris, a recent alluvial deposits; 1669 lava flows and pyriclastic deposits of 1669 AD eruption, lpr-lpd-lpn lava flows and pyriclastic deposits of recent Mongibello; ita lavas from the ancient alkali centres; tf tuffites; Is basal subalkaline lavas; Qa blue-grey marlyclays; c 3D lithological model of study area subsoil, the yellow dots represent the locations of mechanical drillings 
The high fracturing of the lava flows and the porosity of the pyroclastic deposits make these lithotypes highly permeable, with absence of surface water circulation. In the eastern and central part of the river basin, where the town of Valverde is located, there are remobilized tufaceous deposits (tuffites) produced by the water flow action. This kind of volcanic rock, well costipated and with a silty component in its matrix, has a medium-low permeability which favours the surface water circulation. The tuffites are also low-cohesive, so that may be easily weathered with the occurrence of important erosion phenomenon. The east side is characterized by the presence of Pleistocene clays, outcropping to east of a fault system N-S oriented (Romano et al. 1979; Barreca et al. 2013). In this sector of the Settepani river basin, the fluvial network is well developed, due to the low permeability of the clayey soils.

\section{Methodologies used}

In order to identify the trigger factors, which caused some collapses in the down town of Valverde between October 2015 and October 2017, a preliminary study to define the lithotypes present at the site and the respective permeability parameters has been conducted. Furthermore, the rainfall rate in the days before the subsidence phenomenon has been examined and, three geophysical field surveys have been performed using the Electrical Resistivity Tomography (ERT) technique with a 3D electrodes configuration. These have been used to determine the volume of subsoil subjected to subsidence and other potential instable areas. Finally, an analysis of 300 rainfall events, with rainfall depth greater than $1 \mathrm{~mm}$, occurred in the studied area, between January 2015 and February 2018, were performed in order to determine the thresholds values that generate soil piping phenomena.

\subsection{D model of study area subsoil}

In this study 19 mechanical drillings data, related to surveys previously performed in the investigated site, have been used to better understand the stratigraphy of the survey area and to reconstruct a 3D lithological model of the subsoil (Fig. 2c). The logs show the presence of tuffites, lava flows, pyroclastic rocks, clays and fill materials (Fig. 3). For each type of lithology, based on the information reported in the literature (Ferrara 1975, 2010; Ferrara et al. 2001; Ferrara and Pappalardo 2008) has been assigned a numerical value related with their permeability properties for a subsoil water circulation analysis. This has enabled to separate the different lithologies in hydro-geological complexes with 3 permeability categories; 1, 2 and 3 for low, medium and high permeable respectively (Figs. 3, 4a, b). Subsequently, a geo-statistical permeability distribution 3D model has been developed (Fig. 4c), considering the spatial coordinates of the mechanical drillings and the assigned permeability values for each lithotype.

\subsection{Rainfall data analysis}

With the aim to identify the causes that led to the subsidence phenomena (Fig. 5) was carried out a rainfall analysis of the previous periods to the occurrence of such events. To obtain a rainfall analysis, in this study were considered records from 18 rainfall monitoring stations. The Sistema informativo Agrometeorologico Siciliano (Regione Sicilia-SIAS) manage 17 of these rainfall stations and one of them is owned by a private user (Fig. 6a). 


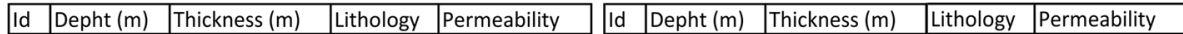

\begin{tabular}{|l|c|c|l|l|}
\hline 1 & $0,0-2,6$ & 2.6 & & \\
\hline 1 & $2,6-4,5$ & 1.9 & & \\
\hline 2 & $0,0-1,0$ & 1 & & \\
\hline 2 & $1,0-5,2$ & 4.2 & & \\
\hline
\end{tabular}

\begin{tabular}{|c|c|c|l|l|}
\hline 10 & $0,0-0,1$ & 0.1 & & \\
\hline 10 & $0,1-2,4$ & 2.3 & & \\
\hline 10 & $2,4-6,3$ & 3.9 & & \\
\hline 10 & $6,3-11,7$ & 5.4 & & \\
\hline 10 & $11,7-15,0$ & 3.3 & & \\
\hline
\end{tabular}

\begin{tabular}{|l|l|l|l|l|}
\hline 3 & $0,0-3,1$ & 3.1 & & \\
\hline 3 & $3,1-5,2$ & 2.1 & & \\
\hline
\end{tabular}

\begin{tabular}{|l|l|l|l|l|}
\hline 11 & $0,0-1,3$ & 1.3 & & \\
\hline 11 & $1,3-4,1$ & 2.8 & & \\
\hline 11 & $4,1-6,2$ & 2.1 & & \\
\hline
\end{tabular}

\begin{tabular}{|l|c|c|l|l|}
\hline 4 & $0,0-0,1$ & 0.1 & & \\
\hline 4 & $0,1-1,2$ & 1.1 & & \\
\hline 4 & $1,2-4,4$ & 3.2 & & \\
\hline 4 & $4,4-9,2$ & 4.8 & & \\
\hline 4 & $9,2-13,0$ & 3.8 & & \\
\hline 4 & $13,0-13,6$ & 0.6 & & \\
\hline 4 & $13,6-15,0$ & 1.4 & & \\
\hline
\end{tabular}

\begin{tabular}{|l|l|l|l|l|l|}
\hline 12 & $0,0-4,3$ & 4.3 & & \\
\hline 12 & $4,3-5,2$ & 0.9 & & \\
\hline
\end{tabular}

\begin{tabular}{|c|c|c|c|c|}
\hline 5 & $0,0-0,1$ & 0.1 & & \\
\hline 5 & $0,1-0,8$ & 0.7 & & \\
\hline 5 & $0,8-5,2$ & 4.4 & & \\
\hline
\end{tabular}

\begin{tabular}{|c|c|c|c|c|}
\hline 13 & $0,0-3,0$ & 3 & & \\
\hline 13 & $3,0-6,1$ & 3.1 & & \\
\hline
\end{tabular}

\begin{tabular}{|c|c|c|l|l|}
\hline 6 & $0,0-0,4$ & 0.4 & & \\
\hline 6 & $0,4-2,7$ & 2.3 & & \\
\hline 6 & $2,7-10,4$ & 7.7 & & \\
\hline 6 & $10,4-15,0$ & 4.6 & & \\
\hline
\end{tabular}

\begin{tabular}{|l|l|l|l|l|}
\hline 7 & $0,0-1,2$ & 1.2 & & \\
\hline 7 & $1,2-4,8$ & 3.6 & & \\
\hline
\end{tabular}

\begin{tabular}{|l|l|l|l|l|}
\hline 8 & $0,0-1,1$ & 1.1 & & \\
\hline 8 & $1,1-1,6$ & 0.5 & & \\
\hline 8 & $1,6-4,5$ & 2.9 & & \\
\hline
\end{tabular}

\begin{tabular}{|l|l|l|l|l|}
\hline 14 & $0,0-0,2$ & 0.2 & & \\
\hline 14 & $0,2-2,8$ & 2.6 & & \\
\hline 14 & $2,8-6,0$ & 3.2 & & \\
\hline
\end{tabular}

\begin{tabular}{|c|c|c|c|l|}
\hline 9 & $0,0-0,4$ & 0.4 & & \\
\hline 9 & $0,4-2,4$ & 2 & & \\
\hline 9 & $2,4-4,5$ & 2.1 & & \\
\hline
\end{tabular}

\begin{tabular}{|c|c|c|l|l|}
\hline 15 & $0,0-1,0$ & 1 & & \\
\hline 15 & $1,0-14,5$ & 13.5 & & \\
\hline 15 & $14,5-16,0$ & 1.5 & & \\
\hline
\end{tabular}

\begin{tabular}{|l|c|c|l|l|}
\hline 16 & $0,0-1,0$ & 1 & & \\
\hline 16 & $1,0-10,0$ & 9 & & \\
\hline
\end{tabular}

\begin{tabular}{|c|c|c|c|c|}
\hline 17 & $0,0-0,4$ & 0.4 & & \\
\hline 17 & $0,4-10,0$ & 9.6 & & \\
\hline
\end{tabular}

\begin{tabular}{|l|l|l|l|l|}
\hline 18 & $0,0-0,4$ & 0.4 & & \\
\hline 18 & $0,4-5,0$ & 4.6 & & \\
\hline
\end{tabular}

\begin{tabular}{|l|l|l|l|l|l|}
\hline 19 & $0,0-0,5$ & 0.5 & & \\
\hline 19 & $0,5-5,0$ & 4.5 & & \\
\hline
\end{tabular}

\begin{tabular}{|c|c|}
\hline & Concrete \\
\hline & Silty-sandy fill soil \\
\hline & Tuffite \\
\hline & Scoriaceous lava with tuffite levels \\
\hline & Fractured lava \\
\hline
\end{tabular}

\begin{tabular}{|l|c|}
\hline & Low permeability \\
\hline & Mean permeability \\
\hline & High permeability \\
\hline
\end{tabular}

Fig. 3 Data relative to the mechanical drillings with associate permeability value (see Fig. 2c for location)

The 17 SIAS stations are located in the eastern part of Sicily, forming a dense network which encloses the volcanic complex of Mt. Etna. The data from the private station were fundamental for this study for its position, inside the Valverde municipality of about $400 \mathrm{~m}$ to N-E from the collapsed area (Fig. 6a).

All the collected data, from a specific considered period, have been plotted on 3D bar graphs (Figs. 8a, 9a, 11a and 13a). The $\mathrm{x}-\mathrm{y}$ plane represents the monitoring station name and the date of the measurement, whereas in the $\mathrm{z}$ axis are reported the rainfall values in $\mathrm{mm}$.

The more significant rain events, recorded at each of the 18 stations, occurred on 1-21 October 2015, 6-7 December 2016 and 26-28 September 2017, were taken into account to construct interpolation maps using the Kriging algorithm method (Cressie 

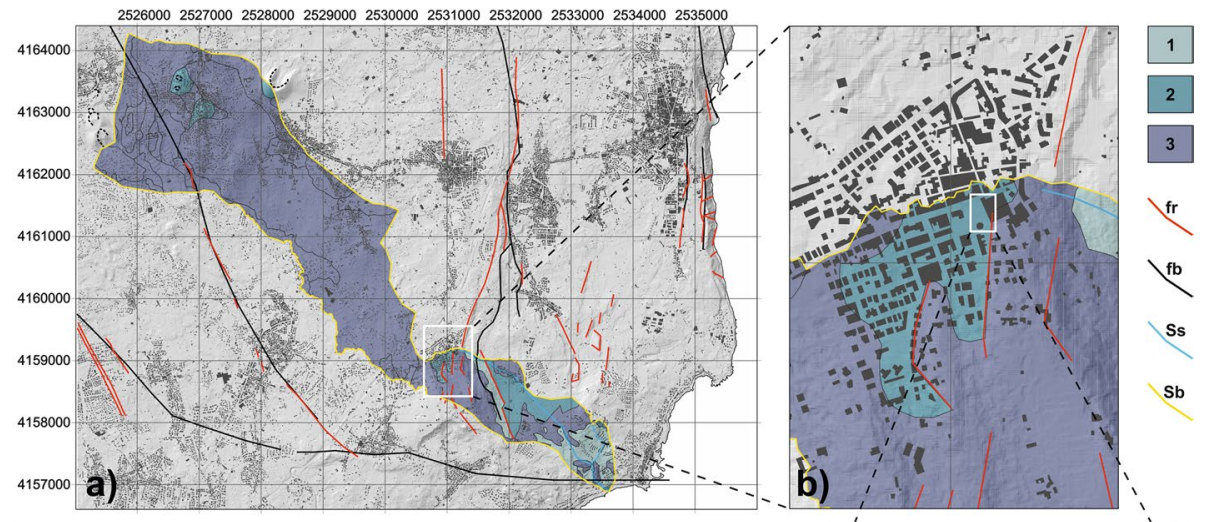

c)

C. Vittorio Emanuele
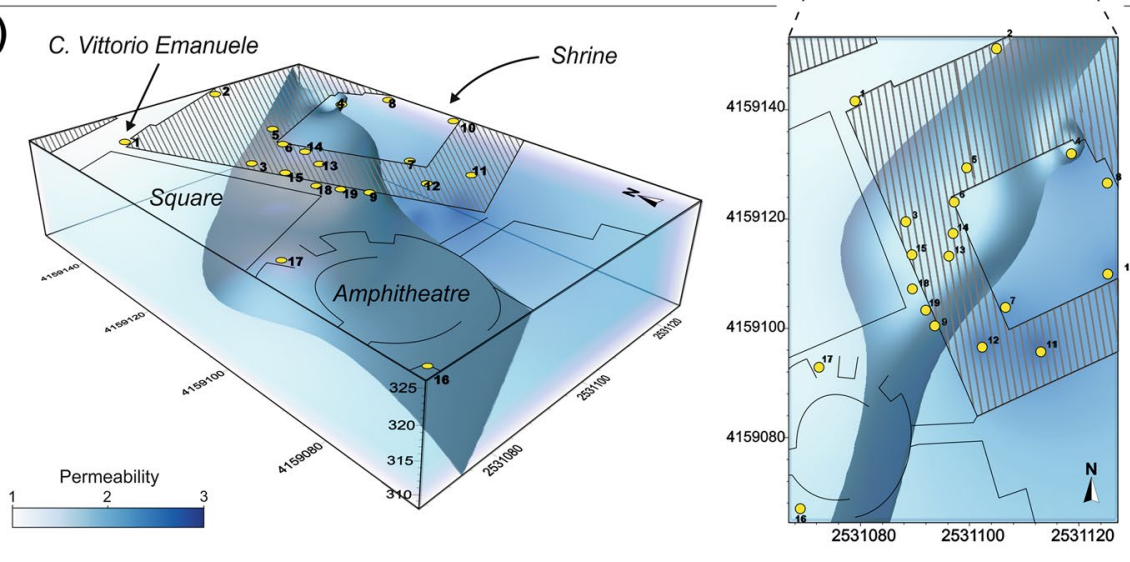

Fig. 4 a, b Settepani basin permeability map: 1 low, 2 middle and $\mathbf{3}$ high permeability; fr faults (from Romano et al., 1979), fb faults (from Barreca et al., 2013), Ss Settepani hydrographic network; Sb Settepani basin; c 3D model of study area subsoil permeability, the yellow dots represent the locations of mechanical drilling

1990; Bigg 1991; Kumar et al. 2016; Pellicone et al. 2018; Millán-Vega et al. 2020). This allowed to obtain isohyets maps with a distribution of the precipitations in the area covered by the stations. Lastly, to quickly correlate the rainfall rates with the topography conditions, the isohyets maps have been superimposed on a Digital Terrain Model (DTM) (Figs. 8b, 9b, 11b and 13b).

The available rainfall data from the private station were further analysed in order to obtain the threshold values for soil piping phenomena in the study area. All the rainfall events occurred between January 2015 and February 2018 were examined (Fig. 14a) selecting only those characterized by rainfall depth greater than $1 \mathrm{~mm}$. For each event, the rainfall intensity was calculated and subsequently these data have been plotted, with respect to duration, on a scatter graph (Fig. 14b). 

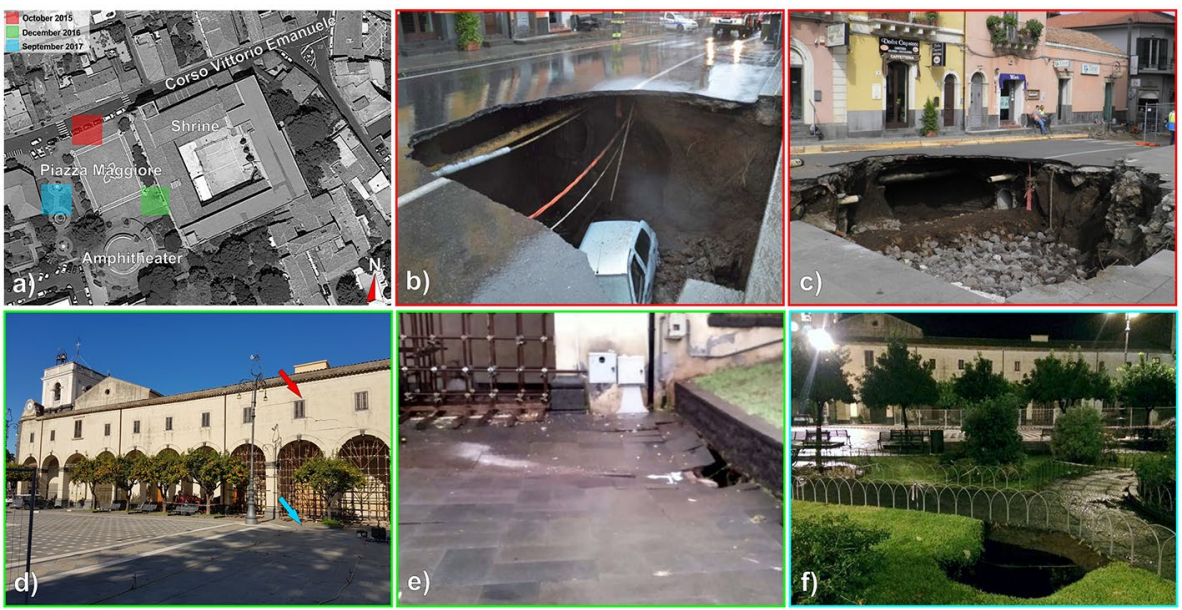

Fig. 5 a Location of areas were the collapse occurred; b, c photo of roadway collapse occurred in October 2015; d, e photo of subsidence happened in December 2016, the red arrow point at structural damages observed on the facade of Maria Santissima Shrine, the blue arrow indicate a soil depression observed near the pillar; $\mathbf{f}$ photo of a collapse occurred in a flowerbed in September 2017

\subsection{Electrical resistivity tomography}

To assess the volumetric extension in the subsoil of the area affected by the subsidence phenomena and identify the presence of additional areas that could be subject to risk, ERT surveys were carried out in 3D configuration.

The Electrical Resistivity Tomography (ERT) is a non-invasive geophysical method with a wide applicability. It enables to produce 2D sections and 3D graphs, which show the subsoil resistivity distribution (Tong and Yang 1990; Sasaki 1992; Griffiths and Barker 1993; Cosentino et al. 1999; Bing and Greenhalgh 2001; Santarato et al. 2011).

The ERT technique is based on the principles of current flow in a medium that in this case is the ground (Archie 1942; Keller and Rapolla 1974; Smith, 1986; Coco and Corrao 2009). A medium can be defined conductive, and then low resistive, when the electric charges which move inside it can easily pass through it. Therefore, this is an important property which vary significantly between materials. In practice, what we measure with the electrical method is not the conductivity or resistivity of materials, but the distortions of the electric potential related with current flow changes in non-homogenous mediums. The measured parameter is then an apparent resistivity, which differs from the actual value of resistivity. Through a process of inversion, which considers the standard deviation principles, by comparing the measured apparent resistivity pseudo-section with theoretical values obtained from a calculated model, it is possible to determine a close to reality resistivity model of the ground (Tong and Yang 1990; Loke and Barker 1996; Cosentino et al. 1999; Martorana et al. 2009, 2017; Santarato et al. 2011). Therefore this technique allows to analyse the electric response of non-homogeneous materials and to achieve, with the interpretation of the final resistivity section, an understanding of the structure and composition of the subsoil.

The typical equipment used in an ERT survey consists of one or more multicore cables connected to a batch of electrodes through take-outs. The electrodes disposition can generally vary in relation with the purpose of the survey and depth of investigation, obtaining 


\begin{tabular}{|l|c|c|c|}
\hline \multicolumn{1}{|c|}{ Comune } & North & East & Altitude (m a.s.l) \\
\hline Antillo & 4203520 & 522917 & 796 \\
\hline Augusta & 4126276 & 513303 & 90 \\
\hline Bronte & 4178677 & 481238 & 424 \\
\hline Catania & 4144073 & 506089 & 10 \\
\hline Cesarò Monte Soro & 4198383 & 473142 & 1840 \\
\hline Cesarò Vignazza & 4187970 & 471815 & 820 \\
\hline Lentini & 4132840 & 493420 & 50 \\
\hline Linguaglossa & 4186715 & 511565 & 590 \\
\hline Linguaglossa Etna Nord & 4182610 & 503056 & 1875 \\
\hline Maletto & 4186704 & 488838 & 1040 \\
\hline Mineo & 4130521 & 475760 & 205 \\
\hline Montalbano Elicona & 4204279 & 497082 & 1250 \\
\hline Paternò & 4152071 & 487181 & 100 \\
\hline Pedara & 4166352 & 504345 & 803 \\
\hline Ramacca Giumarra & 4148383 & 467627 & 263 \\
\hline Randazzo & 4193537 & 498224 & 680 \\
\hline Riposto & 4170912 & 517486 & 50 \\
\hline Valverde & 4159725 & 511193 & 340 \\
\hline
\end{tabular}
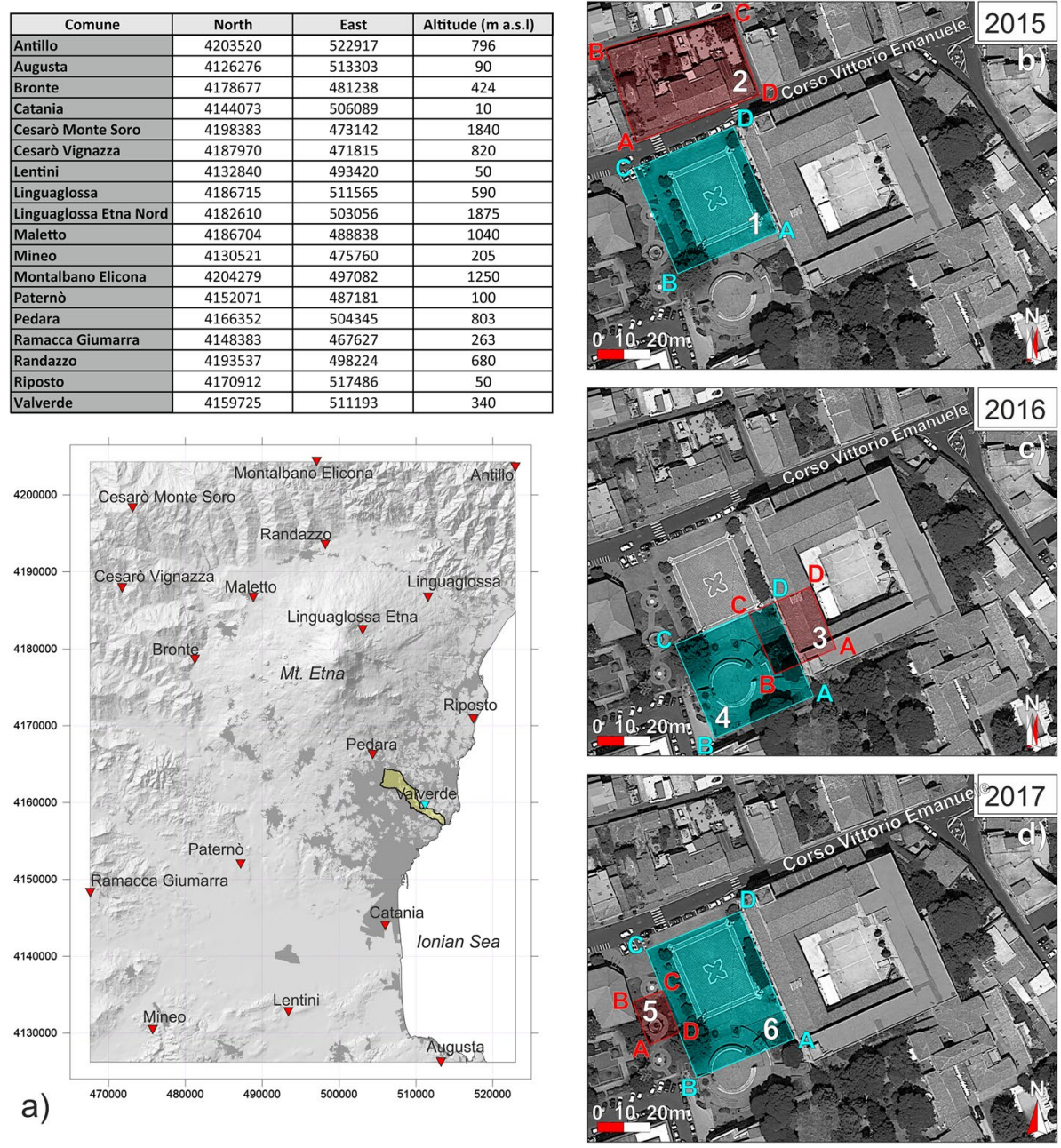

Fig. 6 a Location of rainfall stations, areas subjected to 3D ERT surveys in 2015 (b), 2016 (c), 2017 (d)

also 3D models of the resistivity subsoil distribution. Generally are used conventional electrodes settings, with a regular square grid and constant electrodes spacing. In the last years, new technologies have been developed and irregular geometries, with variable electrodes spacing, are therefore more used. This is possible thanks to more powerful inversion softwares and the employ of Global Navigation Satellite Systems (GNSS) receivers. Nowadays irregular grids and circular or semi-circular geometries are increasingly adopted, in which the electrodes are arranged around the survey area of interest (Santarato et al. 2011; Viero et al. 2015). With these geometries, it is possible to investigate the volume of subsoil under areas where the electrodes placing is problematic.

The electrodes, used both to inject current into the ground and to measure the resultant electrical potential, are stainless steel rods, which are inserted into the soil, or plates used to make this methodology less invasive, although this can increase the ground-electrodes contact resistance. Four electrodes are used for each measure, two to introduce the current 
Fig. 7 3D View of the total number of apparent resistivity data measured at depth (left) and sensitivity plot $\downarrow$ (right) related to ERT surveys carried out: in 2015 around the buildings (a) and at the square (b); in 2016 at amphitheater area (c) and at the Shrine area affected by structural damages (d); in 2017 at public green area (e) and at the square (f)

and the other two to evaluate the electrical potential, with an arrangement called quadripole. The existing resistivity metres automatically switch all the electrodes of the array, so that all of them are exchangeable from current to potential electrodes or vice versa. This enables to vary the spacing and the position of the quadripole along the line increasing the efficiency of the acquisition. The spacing and the position of the quadripole are also related with the configuration used (Wenner, Dipole-dipole, Pole-dipole, etc.,) (Smith 1986; Coco and Corrao 2009; Santarato et al. 2011; Pazzi et al. 2018).

In this study, for all the geophysical field surveys was used a resistivity metre equipped with 4 cables of 24 channels each, with a spacing of $5 \mathrm{~m}$. The electrodes were placed into the ground with different arrangement, for all the acquisitions, a pole-dipole quadripole was used (Table 1). This geometry is effective due to its stable and constant signal, fine resolution and good investigation depth.

All the electrodes were georeferenced through a GNSS antenna (average 3D coordinates accuracy of $2 \mathrm{~cm}$ ) in real time cinematic modality (Pazzi et al. 2016, 2018). This allowed to include the topography data of the survey area in the inversion software, achieving a more accurate final model.

The first field survey, was carried out on 22 and 23 October 2015 (Table 1). Two 3D ERT were performed using 96 electrodes arranged along a grid with regular mesh, with an interelectrode spacing of $3 \mathrm{~m}$. The third ERT, performed in order to investigate the foundation subsoil of private buildings, was carried out using 72 electrodes placed around the buildings perimeter with an interelectrode spacing of $2 \mathrm{~m}$.

During the second field survey, on 10 December 2016, following the subsidence phenomena that affected the square and the Shrine, were performed two 3D electrical tomographies partly overlapping, respectively constituted by 72 (Fig. 6c-3) and 96 (Fig. 6c-4) electrodes, using the same electrode spacing, equal to $3 \mathrm{~m}$ (Table 1).

Table 1 ERT field surveys features

\begin{tabular}{|c|c|c|c|c|c|c|c|}
\hline $\begin{array}{l}\text { ERT } \\
\text { survey }\end{array}$ & $\begin{array}{l}\text { Survey } \\
\text { area }\end{array}$ & $\begin{array}{l}\text { Electrode } \\
\text { configuratio }\end{array}$ & $\begin{array}{l}\text { Number of } \\
\text { electrodes }\end{array}$ & $\begin{array}{c}\text { Electrode } \\
\text { spacing }\end{array}$ & $\begin{array}{l}\text { Number of } \\
\text { quadripoles }\end{array}$ & Misfit \% & $\begin{array}{l}\text { 3D electrode } \\
\text { geometry }\end{array}$ \\
\hline \multirow{2}{*}{$\begin{array}{c}22-23 \\
\text { October } \\
2015\end{array}$} & $\begin{array}{l}\text { Around the } \\
\text { buildings }\end{array}$ & Pole-dipole & 72 & $2 \mathrm{~m}$ & 13.254 & 8.509692 & 唯 \\
\hline & Square & Pole-dipole & $\begin{array}{c}192 \\
(96+96)\end{array}$ & $3 \mathrm{~m}$ & 19.811 & 6.678030 & ינ: \\
\hline \multirow{2}{*}{$\begin{array}{c}10 \\
\text { December } \\
2016\end{array}$} & Amphitheater & Pole-dipole & 96 & $3 \mathrm{~m}$ & 16.661 & 4.119627 & : \\
\hline & Shrine & Pole-dipole & 72 & $3 \mathrm{~m}$ & 1.889 & 5.398406 & 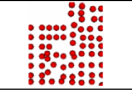 \\
\hline \multirow{2}{*}{$\begin{array}{c}29-30 \\
\text { September } \\
2017\end{array}$} & $\begin{array}{l}\text { Public green } \\
\text { area }\end{array}$ & Pole-dipole & 48 & $3 \mathrm{~m}$ & 2.027 & 12.028741 & \\
\hline & Square & Pole-dipole & $\begin{array}{c}250 \\
(72+82+96)\end{array}$ & $3 \mathrm{~m}$ & 20.680 & 10.047092 & \\
\hline
\end{tabular}




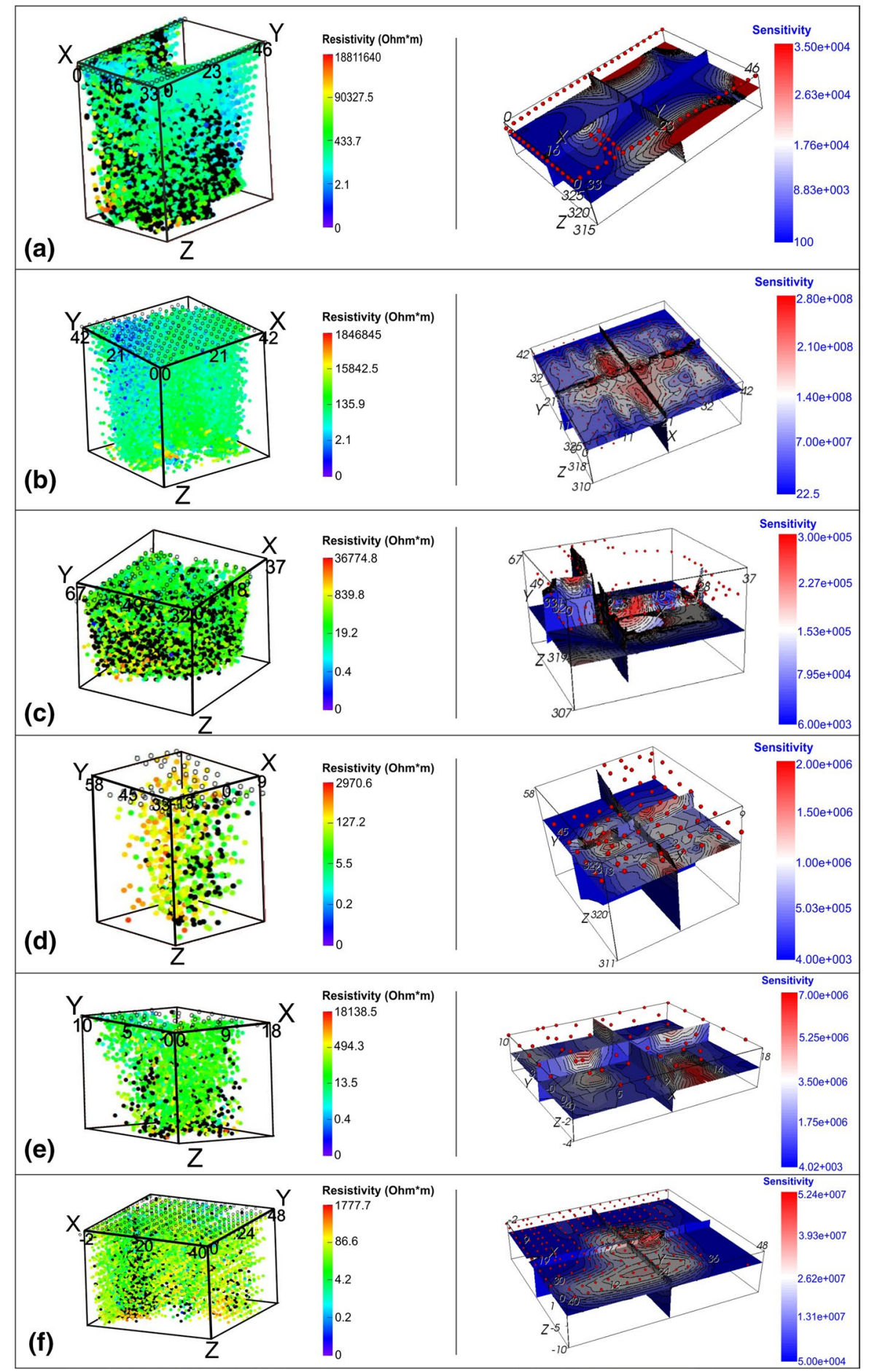


(a)
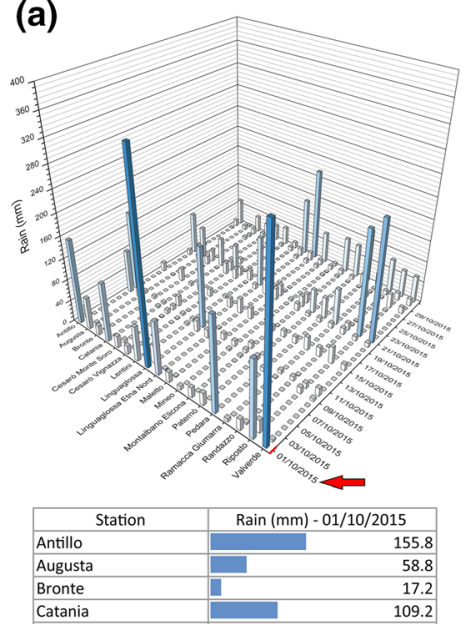

Cesarò Monte Soro

Cesarò Vignazza

Lentini

Linguaglossa

Linguaglossa Etna Nord

Maletto

Mineo

Montalbano Elicona

Paternò

Pedara

Ramacca Giumarra

Randazzo

Riposto

Valverde (b)

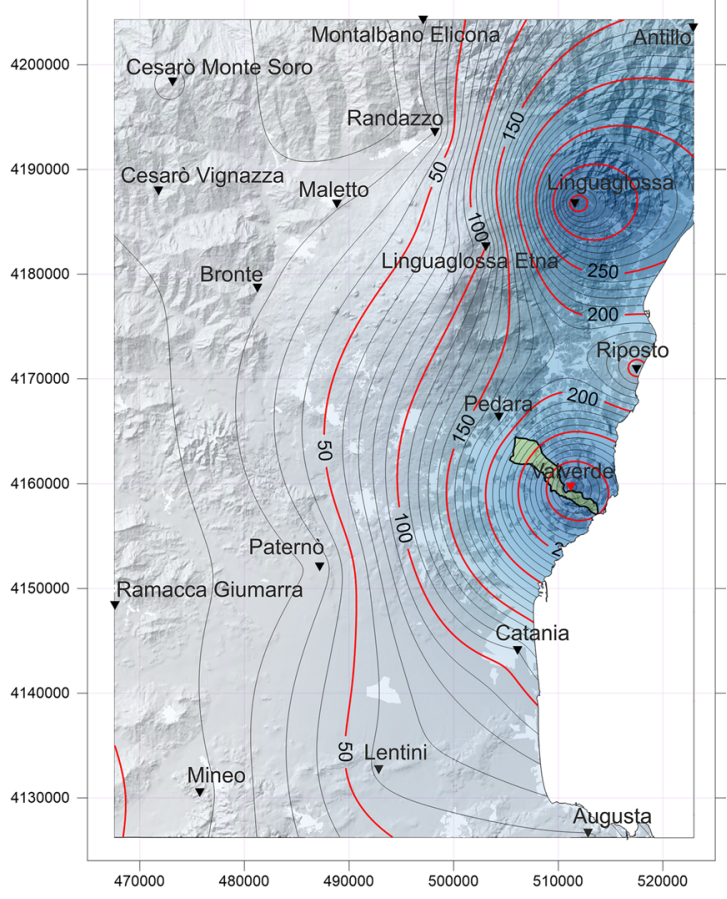

Fig. 8 a 3D bars graph related to October 2015 rainfall data recorded by the stations, table showing the rainfall data of October 01 ; b isohyets map obtained interpolating rainfall data of October 01 recorded by the stations

Four 3D ERT surveys were carried out during the last field survey on 29 and 30 September 2017, one in correspondence with the public green area and three on the Piazza Maggiore (Fig. 6d; Table 1), using an electrode spacing, even in this case equal to $3 \mathrm{~m}$. The survey performed on public green area (Fig. 6d-5) was carried out using 48 electrodes, while the investigations carried out on the square (Fig. 6d-6), were performed using 96, 72 and 82 electrodes respectively (Table 1 ).

To perform the 3D-ERT inversions was used the ErtLab@ software which, through the Occam's regularization, allows to accurately handle datasets acquired in noisy environments (Constable et al. 1987; De Groot-Hedlin and ConsTable 1990; Santarato et al. 2011; Viero et al. 2015; Pazzi et al. 2018). After an accurate data filtering with a statistical analysis, the software executes the necessary iterations for a single inversion. The results of iterations, related each to a specific 3D-ERT datasets (Fig. 7), have shown a good correlation between them (Table 1). Therefore, the models from the last iteration, with the lowest standard deviation between measured and calculated data, were selected for the following interpretation (Santarato et al. 2011; Viero et al. 2015). 


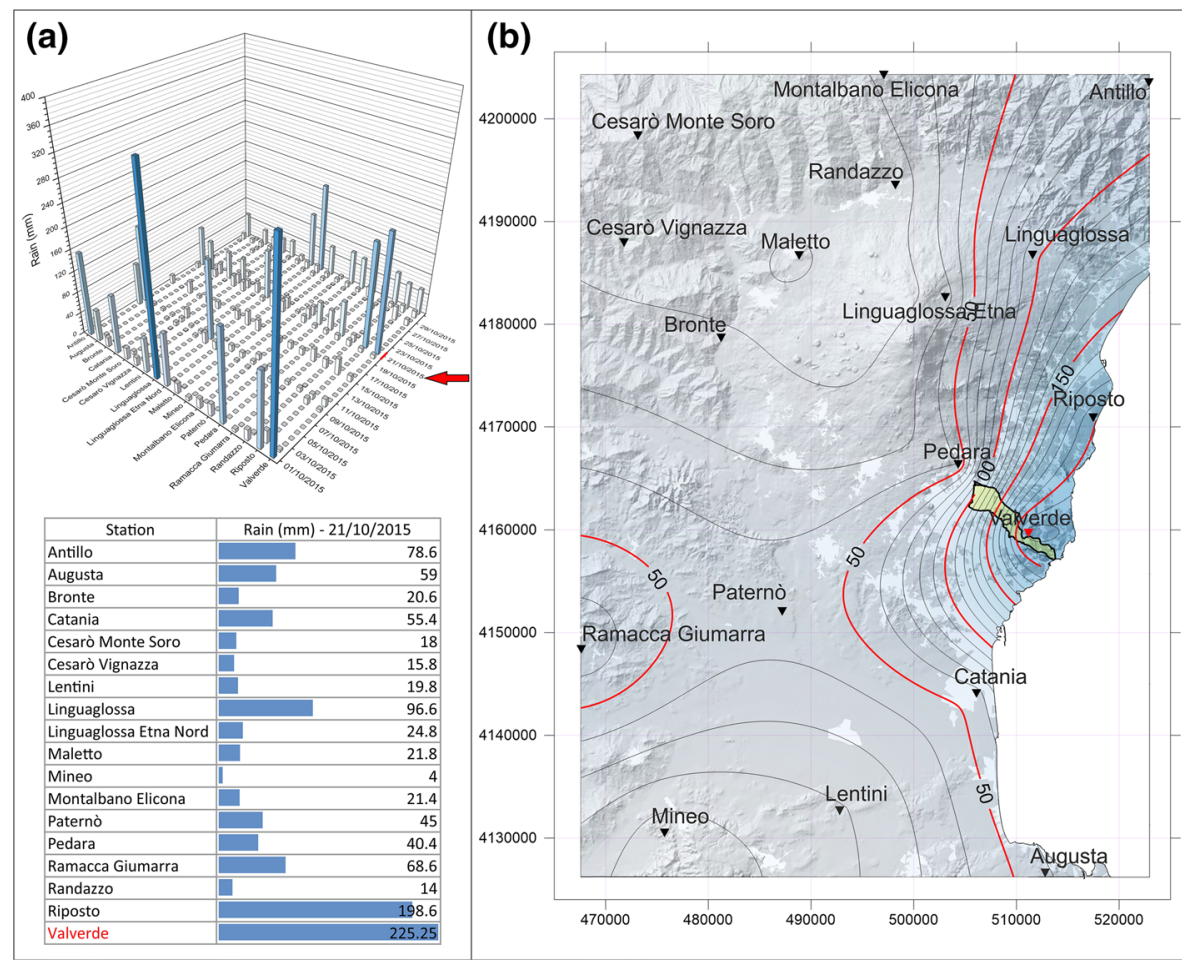

Fig. 9 a 3D bars graph related to October 2015 rainfall data recorded by the stations, table showing the rainfall data of October 21 ; b isohyets map obtained interpolating rainfall data of October 21 , recorded by the stations

\section{Results}

\subsection{D lithological reconstruction and geo-statistical permeability distribution 3D model}

The 3D lithological reconstruction (Fig. 2c) obtained from the interpolation of the data relating to the 19 drillings (Fig. 3), previously carried out in the study area, shows that the subsoil of the area is characterized by the presence of tuffites in the north-west sector, the south-east sector is instead characterized by the presence of pyroclastic levels and fractured lava. A sharp boundary is observable between these two sectors, which can be linked with some tectonics elements reported in previous studies, like a fault, or related with a lava flow boundary (Romano et al. 1979; Branca et al. 2011; Barreca et al. 2013).

The same sharp boundary is highlighted by the geo-statistical permeability distribution 3D model (Fig. 4c). It is indeed possible to divide the considered area in two zones characterized by different permeability values, which it is low at the north-west and high at the sud-east portion respectively. These results are confirmed by some previous geological studies of the same area (Ferrara and Pappalardo 2008).

Regardless of its origin, it is certainly that this geological limit determines the groundwater flow. 


\subsection{October 2015}

At about 2.15 p.m. on 21/10/2015, an extensive subsidence of the road surface occurred in the historic center of the Valverde municipality, in Corso Vittorio Emanuele near to Piazza Maggiore (Fig. 5 a, b, c). This subsidence led to the formation of a chasm of about $30 \mathrm{~m}^{2}$ wide and $4 \mathrm{~m}$ deep into which a parked car falled. Inside the chasm was observed a break in the pipeline of the white water regimentation system, noting that the consequent leak of the water had cause the leaching of the tuffites towards areas characterized by greater permeability.

In order to determine the causes of the subsidence, in a first phase, an analysis of rainfall data relative to October 2015 was performed. Observing the data relating to the various Etna rainfall stations, it is immediately evident that two more intense rain events, which occurred respectively 1 and 21 October, involved the eastern side of Etna
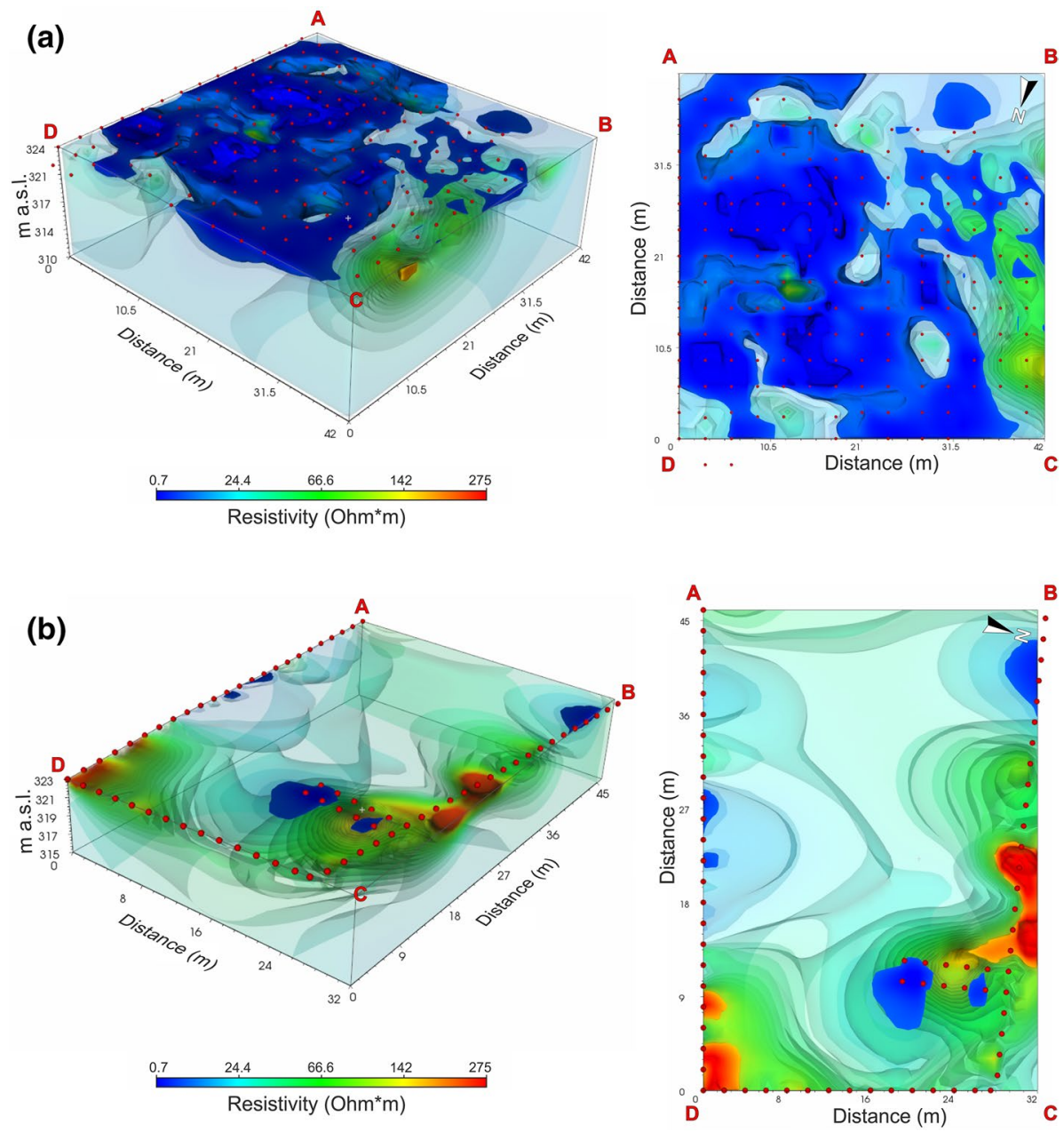

Fig. 10 a 3D model related to the ERT surveys performed at the square (see Fig. 6b-1); b 3D model related to ERT survey carried out around the buildings (see Fig. 6b-2) 
(a)
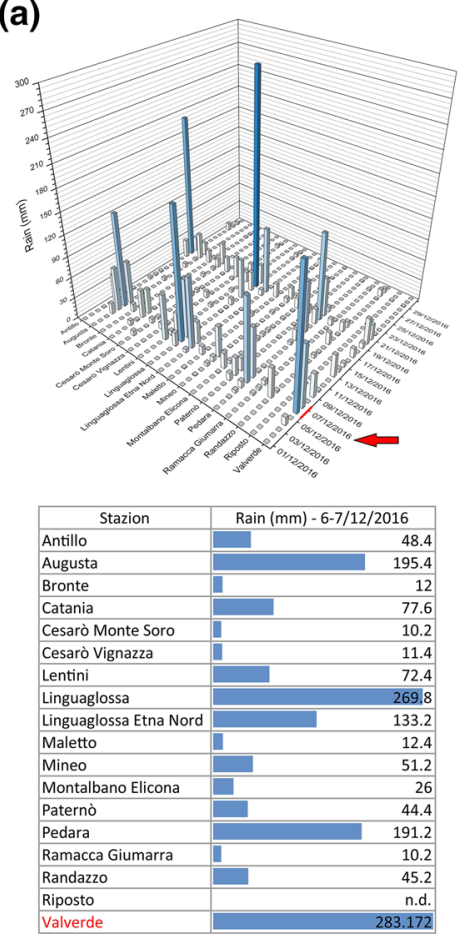

(b)

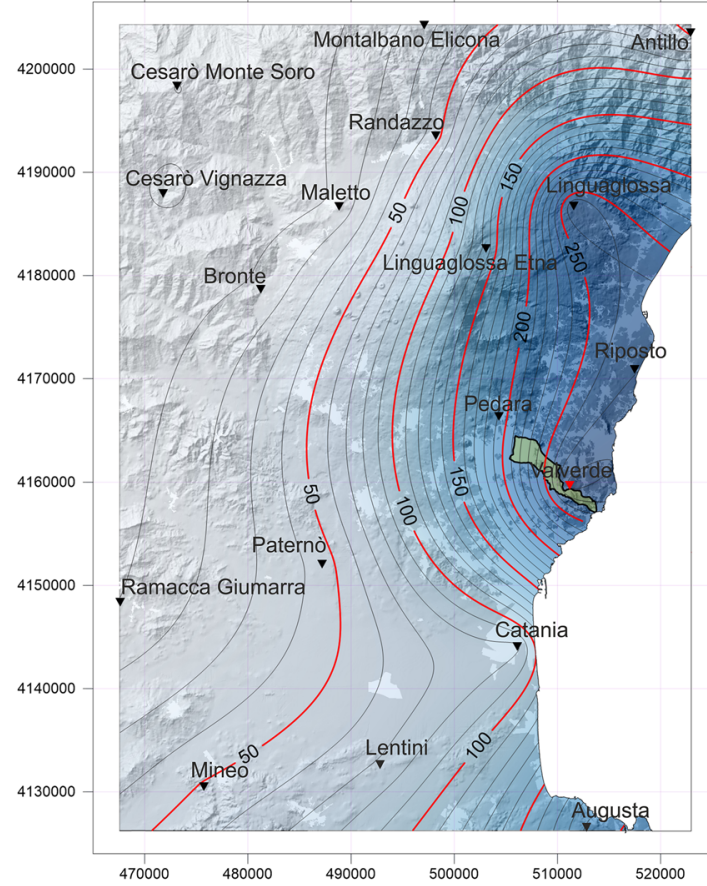

Fig. 11 a 3D bars graph related to December 2016 rainfall data recorded by the stations, table showing the cumulated rain values of December 06-07; b isohyets map obtained interpolating cumulated rain values of December 06-07, recorded by the stations

(Figs. 8, 9). The isohyets map obtained interpolating rainfall data of 1 October (Fig. 8b), show that, while on the western side the precipitations were limited and sometimes not significant, this meteorological event affected intensively the entire Etna eastern slope. This type of phenomenon, particularly frequent in Etnean climate, is linked to the meeting of hot and humid currents coming from E and ESE, with the orographic barrier (Mt. Etna), which give rise to the Stau effect on the eastern side and the Fhon effect on the western one (Caccamo et al. 2017; Raffaele et al. 2020). On 1 October, the most significant rainfall was recorded at Linguaglossa and Valverde stations, respectively 365 and $348 \mathrm{~mm} /$ day (Fig. 8a). By the isohyets map, it can be seen that the entire basin of the Settepani stream was affected by rainfall $>200 \mathrm{~mm} /$ day.

On 21 October, the Etna eastern slope was affected by a second intense meteoric event. The data highlight that the stations that recorded the greatest rainfall were Valverde (225.25 mm/day) and Riposto (198.6 mm/day) (Fig. 9a). From the isohyets map relating to daily rainfall (Fig. 9b), it can be notice that the perturbation for this rainfall event was less extensive than that which occurred on 1 October, but even in this case, the Settepani basin was affected by a considerable precipitation rate, in the range $\sim 90-230 \mathrm{~mm} /$ day.

In order to identify the presence in the subsoil of further cavities, which could lead to the occurrence of other subsidence phenomena, and to define a model of water circulation in the subsoil, a field survey was carried out. This field survey consisting of three 3D 
electrical tomographies, two of which on Piazza Maggiore and one around private buildings, located near the chasm (Fig. 6b, Table 1).

The data obtained from the two tomographies carried out on the square were jointly inverted in order to reconstruct a 3D model of the resistivity distribution in the subsurface of the entire survey area (Figs. 6b-1, 10a). The model obtained shows the presence of a large low-resistive volume ( $\sim 0.7-10 \Omega * \mathrm{~m})$, which can be correlated to the presence of humid tuffites, extending approximately in NNW-SSE direction. The depth of this lowresistive volume varies from about $8.5 \mathrm{~m}$ in the south area of the square and wear thin gradually, away radially from this point.

On the west side, the low-resistive volume is confined by a medium-high resistivity area (150-200 $\Omega * \mathrm{~m}$ ) which can be attributable to the presence of a probable cavity or to not very compact ground. On the other sides of the square the low-resistive volume is not confined, therefore, considering the mechanical drillings data and the geostatistical estimate of the permeability distribution, it is possible to hypothesize that this low-resistive volume extends beyond the survey area towards East, probably below the adjacent Shrine.

The resistivity model obtained by the 3D ERT performed around the buildings (Figs. 6b$2,10 \mathrm{~b})$ show average resistivity values, which can be correlated to the lithotypes present in the subsoil. Small low-resistivity volumes $(\sim 0.7-10 \Omega * \mathrm{~m})$, with reduced thickness, equal to about $0.5 \mathrm{~m}$, are observed near Corso Vittorio Emanuele. This area, close to the one where the chasm occurred, could be related to the water circulation below the road surface caused by the rupture of the pipeline. Furthermore, there are two other low-resistive zones characterized by a thickness between 0.5 and $1 \mathrm{~m}$. The first, located at a manhole inside the building's courtyard, could be due to the disposal of white water from the structure. The second low-resistive zone is located in correspondence with two small masonry buildings, with an apparent poorly waterproofed base, that could favour the conveyance and infiltration of water. Thus allowing to exclude the hypothesis that this area may be linked to the water circulation that caused the road surface subsidence.

There are also two high-resistive volumes $(\sim 200-275 \Omega * \mathrm{~m})$, with a thickness between 0.5 and $1 \mathrm{~m}$, probably due to the presence of non-compacted soils and characterized by the existence of small cavities.

In the months following the occurrence of the event, the city administration took steps to restore the roadway. The pipeline of the white water regimentation system was restored and the chasm was filled with boulders and concrete at the bottom while in the superficial part with natural aggregates. A system of conduits which collects and conducts urban white water in Settepani torrent was also created.

\subsection{December 2016}

In December 2016, subsidence was observed in the flooring of the southern sector of Piazza Maggiore and on the adjacent structure of the Maria Santissima di Valverde Shrine (Fig. 5a, d, e). Even in this case the disasters occurred in conjunction with a rainfall event that took place between 6 and 7 December, which affected part of eastern Sicily and in particular the eastern side of Etna. From the results obtained by the rainfall analysis, it is clear that the meteorological dynamics are similar to those found in October 2015.

The data relating to the rainfall stations, show that the greatest values for the cumulated rainfall were recorded at Valverde $(283.17 \mathrm{~mm})$ and Linguaglossa $(269.8 \mathrm{~mm})$ 

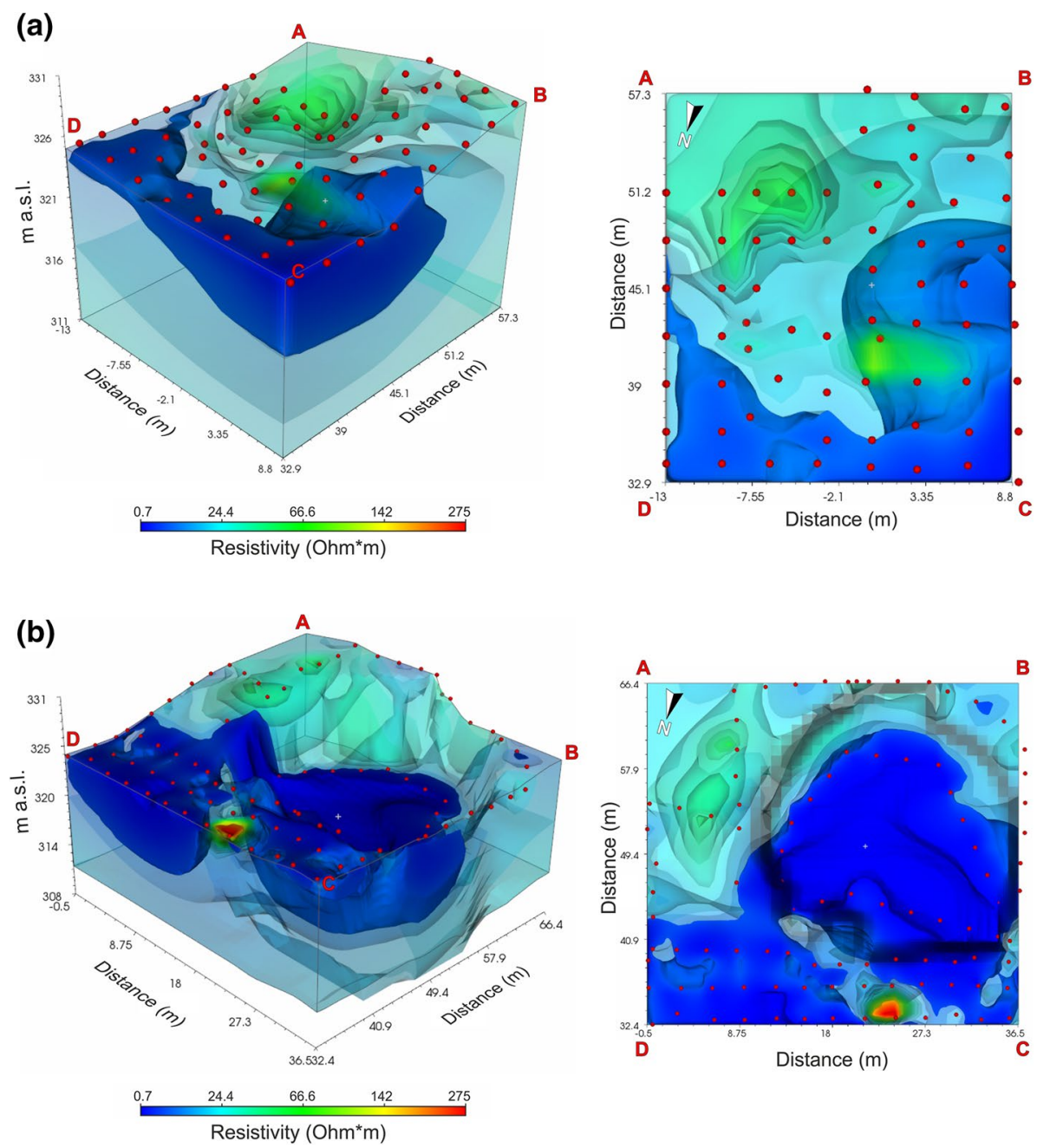

Fig. 12 a 3D model related to the ERT survey performed at the Shrine area affected by structural damages (see Fig. 6c-3); b 3D model related to ERT survey carried out at amphitheater area (see Fig. 6c-4)

stations (Fig. 11a). From the isohyets map obtained adding up the daily rainfall relating to 6 and 7 December (Fig. 11b), it is possible to note how the maximum rainfall, involves the Etna eastern sector, affected mainly the coastal and foothill areas. In particular, the Settepani basin is characterized by a rainfall rate of about $\sim 210-290 \mathrm{~mm}$.

Following the subsidence phenomena that affected the square and the Shrine, two 3D electrical tomographies were performed (Fig. 6c, Table 1) in order to identify any cavities, as well as the presence of humid areas and therefore subject to water circulation.

The electroresistive models obtained from the surveys elaboration (Fig. 12a, b) show a low-resistive area $(\sim 0.7-15 \Omega * \mathrm{~m})$ correlated to the presence of humid tuffites, which affects the NE sector for almost all amphitheatre area. This volume, which reaches a depth of about $14 \mathrm{~m}$, is not confined only in the model northern part, next to the square. This low-resistive area, characterized by resistivity values comparable to those observed in the 
(a)
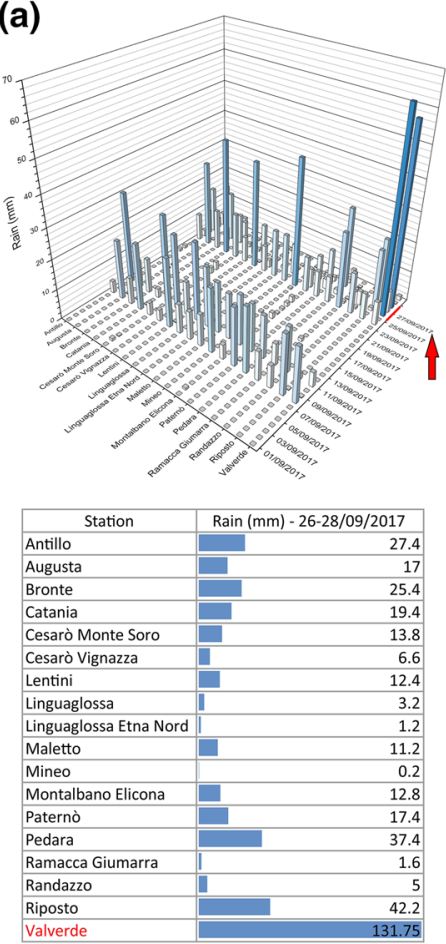

(b)

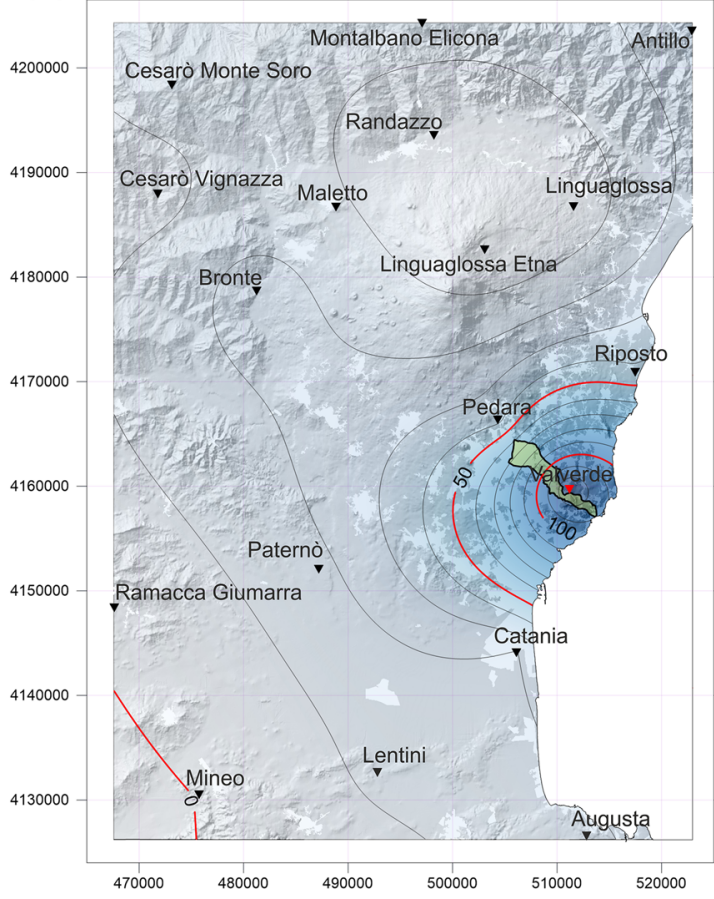

Fig. 13 a 3D bars graph related to September 2017 rainfall data recorded by the stations, table showing the cumulated rain values of September 26-27-28; $\mathbf{b}$ isohyets map obtained interpolating cumulated rain values of September 26-27-28, recorded by the stations

tomographies carried out following the 2015 event, and in agreement with them for geometric continuity, confirms the hypotheses made following the surveys previously carried out on the square, which showed an extension towards south of the low-resistive block. Even in this case, the geometry of the low-resistive volume is indicative of a subsoil water flow in lavas direction, which are characterized by higher permeability values.

In the NW sector of the investigated area, near a maintenance room, is present a high-resistive zone. Another area characterized by medium-high resistivity values is observable in the SE direction. In this second zone, mechanical drillings revealed the presence of fractured lavas, the resistivity values identified are therefore compatible with the lithotypes present.

The actions taken to secure the structures affected by the subsidance, and to prevent possible collapse consisted in filling the cavity formed on the main square near the shrine through a concrete casting. In particular, about $50 \mathrm{~m}^{3}$ of concrete were injected in the first phase, to which another $10 \mathrm{~m}^{3}$ were subsequently added. Finally, 2 tons of expanding resin were injected.

\subsection{September 2017}

Between 26 and 28 September 2017, further flooring subsidence phenomena was observed in some sectors of Piazza Maggiore and within the adjacent public green area 

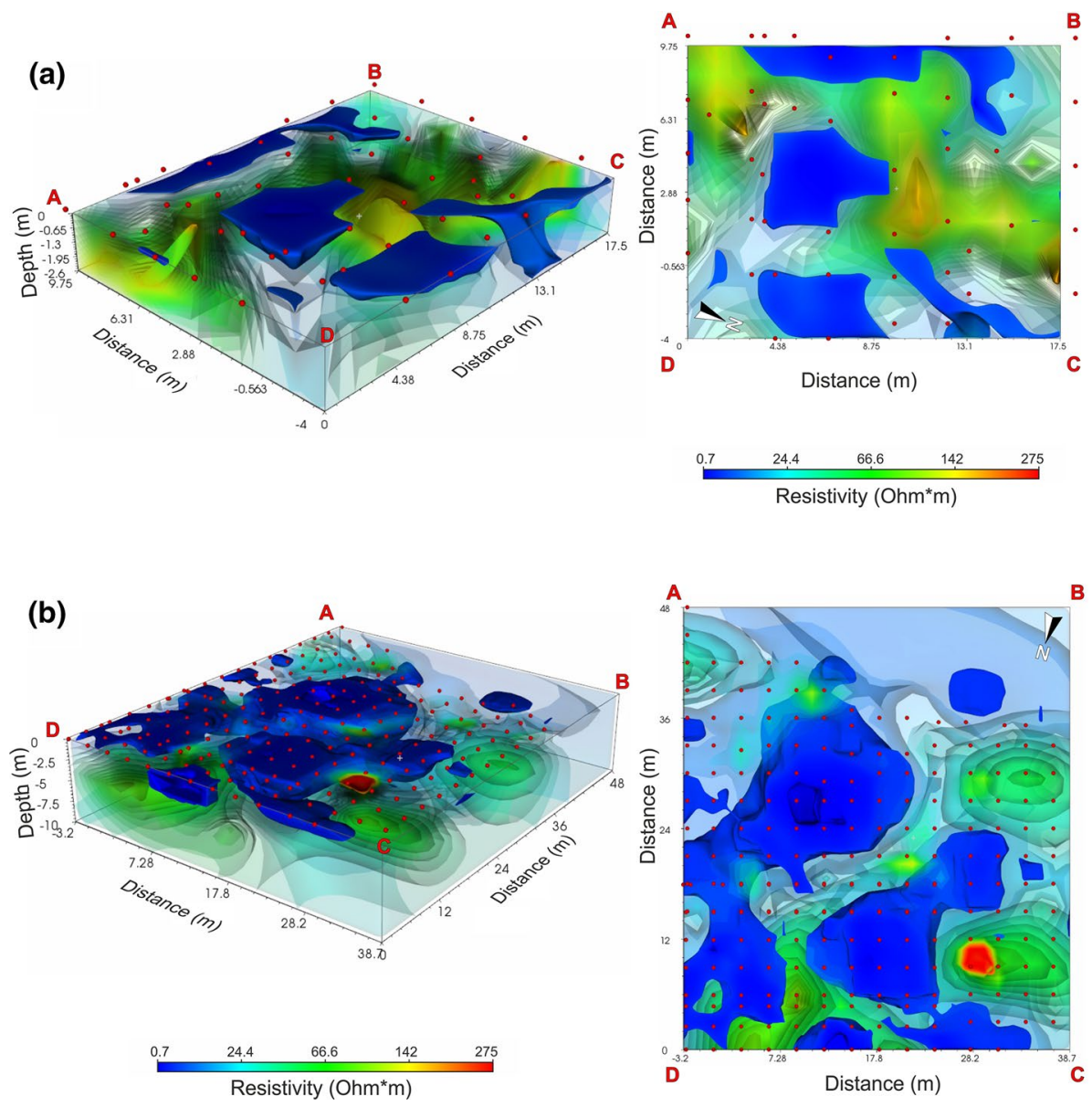

Fig. 14 a 3D model related to the ERT survey performed at public green area (see Fig. 6d-5); b 3D model related to ERT surveys carried out at the square (see Fig. 6d-6)

(Fig. 5a, f). Once again, the subsidence occurred in conjunction with short, but intense, rainfall events.

The graphical representations obtained by the analysis of rainfall data show clearly that the Valverde rainfall station, during the three days, have accumulated significantly higher rainfall rates than the other Etna stations (Fig. 13a). Therefore, in this case the meteorological dynamics that affected the area differ from those observed in the previous cases, as it is a particularly localized event, which does not extensively affect the eastern Etna side (Fig. 13b).

With the aim to define the triggering causes and the extent of the subsidence, four 3D ERTs were performed, one in correspondence with the public green area and three on the Piazza Maggiore (Fig. 6d; Table 1). Even in this case, during the processing phase, the data obtained from the three surveys carried out on Piazza Maggiore were jointly inverted and a single 3D electroresistive model was obtained (Fig. 14). 
The 3D electrical tomography performed in the public green area (Figs. 6d-5, 14a) showed a random distribution of low resistive and high resistive areas. Therefore, a subhorizontal water flow is not evident, but instead the water tends to disperse vertically into the subsoil due to slow infiltration. The presence of several defined high-resistance areas indicates that there are zones that are not very compact or even the presence of voids, probably formed due to the erosive action of the waters that tend to infiltrate downwards. In the central area of the model, in correspondence to a public fountain, there is a defined

(a)

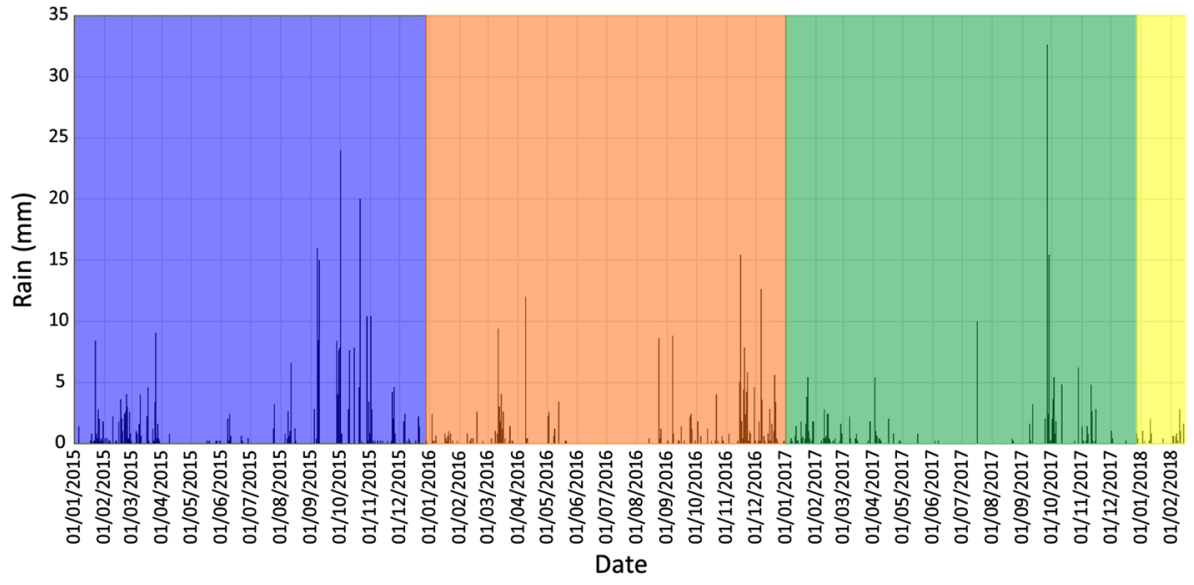

(b)

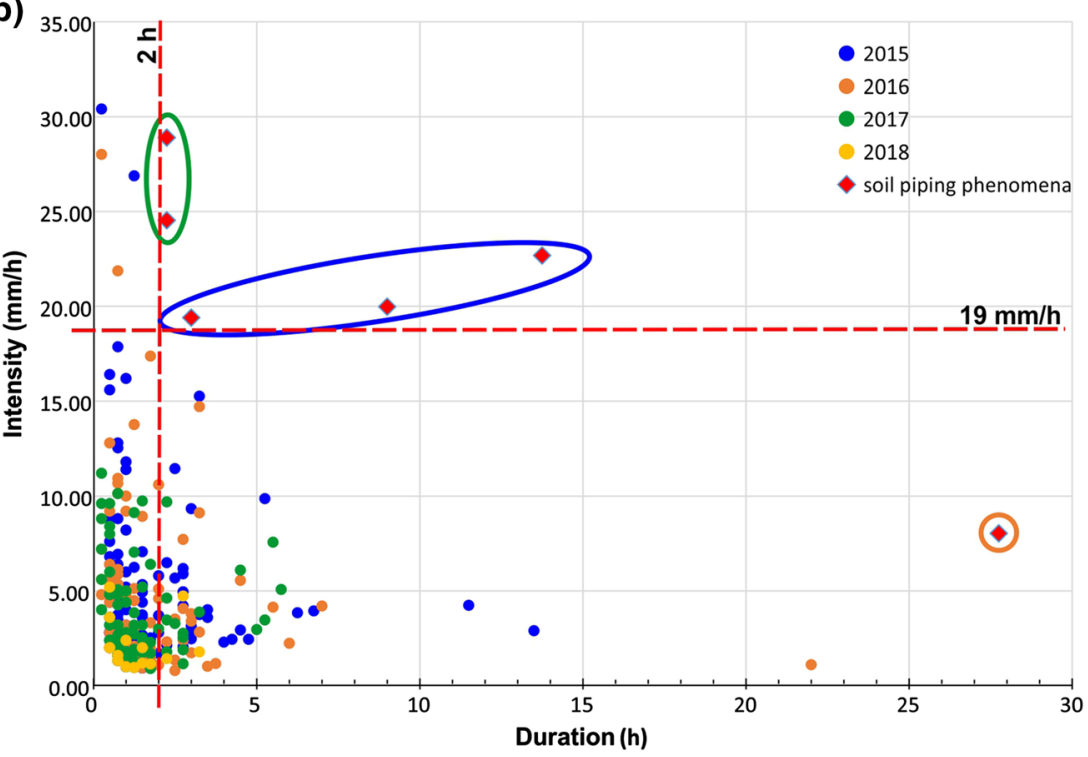

Fig. 15 a Bars graph related to rainfall data recorded by Valverde station, between January 2015 and February 2018; b scatter graph, of the rainafall intensity related to the analysis of 300 rainfall events characterized by a rainfall depth greater than $1 \mathrm{~mm}$, the dashed red lines show the threshold values for soil piping phenomena identified for the studied area 
low-resistive volume approximately $1.5 \mathrm{~m}$ thick, probably due to the dispersion of water in the subsoil. Another low-resistive volume that needs to be attention is located to the NE. This laterally confined volume reaches up to the maximum investigated depth, about $2.60 \mathrm{~m}$, so it is possible to suppose that this area may be affected in the future by a phenomenon know as hydrodynamic instability or siphoning. This phenomenon occurs when the intergranular forces are cancelled, and consequently the ground resistance is cancelled too, thus the solid particles can be transported from moving water, giving rise to a progressive erosion phenomenon that leads to the collapse of the soil structure.

The 3D electrical tomographies carried out on the square (Figs. 6d-6, 14b) show a large low-resistive area that geometrically overlaps that found in the 3D electrical tomography carried out in 2015. Despite a geometric similarity, it is evident that the low resistive area is less extensive both laterally, both in depth. Laterally confined, apart from some small area on the eastern side, in depth it extends up to a maximum of $7.4 \mathrm{~m}$. The presence of a less extensive low-resistive volume indicates a lower water circulation in the subsoil, partly linked to the lower rate of rainfall and partly to the numerous interventions carried out in the area in previous years, in order to restore the white water regimentation system and mitigate subsurface subsidence phenomena.

In order to restabilising the condition of stability and continuity in the ground, following the subsidence phenomena occurred in September 2017, a total filling of cavities through the laying of granular material and concrete casting were performed.

\subsection{Threshold values determination for soil piping phenomena}

The scatter graph (Fig. 15b), related to the analysis of 300 rainfall events characterized by a rainfall depth greater than $1 \mathrm{~mm}$, shows how the events that gave rise to the soil piping phenomena differ markedly from the other rain events occurred between January 2015 and February 2018 (Fig. 15). Unlike the rain events that usually occur in the study area, characterized by not particularly high intensity and/or duration, the events that gave rise to the soil piping phenomena that took place in 2015 and 2017 have a fairly high intensity and a significant duration. In particular, the rainfall events of October 2015 are characterized by a rainfall intensity ranging between 19 and $23 \mathrm{~mm} / \mathrm{h}$ and a duration ranging from 4 to $14 \mathrm{~h}$. The rainfall events of September 2017 are distinguished by a rainfall intensity of 25 and $29 \mathrm{~mm} / \mathrm{h}$ and a duration that exceeds two hours. It is therefore possible to identify threshold values for soil piping phenomena in the study area equal to $19 \mathrm{~mm} / \mathrm{h}$ as regards rainfall intensity and $2 \mathrm{~h}$ for duration. An exception is the event of December 2016, which, although not presenting a rainfall intensity $(8 \mathrm{~mm} / \mathrm{h})$ higher than that identified as the threshold value, is characterized by a particularly high duration that reaches $28 \mathrm{~h}$ of continuous rainfall.

\section{Discussion}

It is clear that the occurrence of sudden subsidence phenomena within a residential area, such as those that occurred between 2015 and 2017 in the Valverde municipality, represent a serious problem for public safety. Therefore, studies and interventions must be put in place to prevent this phenomenon and to immediately identify the causes and the possible development. In this study a methodological approach is presented, which consists of a rainfall data analysis and the execution of ERT geophysical surveys, in order to study 
the causes and possible development of soil piping phenomena occurring within densely urbanized areas.

In a densely urbanized area even a bad disposal of white water can contribute to the formation of soil pipe, but the causes of such phenomena are mainly to be found in the climatic, geomorphological and lithological characteristics of a given area.

The weather conditions in a specific area, as well as being influenced by the climate on a regional scale, often show local peculiarities mainly due to geomorphological characteristics. These sometimes leads to the development of localized microclimates, affecting small areas (Costantini et al. 2013; Poudulis and Takemi 2016; Caccamo et al. 2017; Martinotti et. al 2017), such as the one where the investigated site is located. Stau effect is one of these localized phenomena, one of the best known in the presence of orographic barriers, including volcanoes (Costantini et al. 2013; Caccamo et al. 2017). The rainfall events that affect these areas are abundant and often trigger hydrogeological instability.

In this study, it was possible not only to define the triggering factor of soil piping phenomena, identified in the high rainfall rates, but also to evaluate the thresholds beyond which erosion processes begin to occur which lead to the formation of underground cavities that can collapse generating real chasms in the ground.

It clearly emerges, in particular from the event that occurred in October 2015, that the rainwater control and disposal system was not efficient, probably due to poor maintenance, or due to breakages related to tectonic stress, or even because not adequately sized.

The preliminary and detailed geological study of the area was carried out through a geological survey, also exploiting the information present in the literature and the data relating to 19 mechanical drillings previously carried out in correspondence with the study area. This allowed us to obtain a well-defined picture of the lithostratigraphic sequences present in the area. The presence of a lateral variation clearly emerges (probably due to the presence of an edge of lava flow or to a tectonic structure), which puts tuffites and lavas in contact. These lithotypes have different permeability values. The geostatistical analysis of the permeability values, in addition to confirming and better defining the geometry of the lateral variation, gives a clear indication regarding the outflow routes of subsurface waters, which move from the less permeable areas towards those with greater permeability, from NW to SE. As highlighted by many scientific researches (Toulkeridis et al. 2016; Wilson et al. 2018; Yano et al. 2019; Pereyra et al. 2020; Wu et al. 2020) the presence of open fractures in the lavas and the easy erodibility of the tuffites favour the migration of the latter towards the fractures, with consequent siphoning phenomena and therefore superficial subsidence.

The rainfall analysis has highlighted how the eastern side of Etna is particularly subject to intense and continuous rainfall events, of a sub-tropical nature and with high precipitation rates. Most of the meteoric water in this area, thanks to the presence of very permeable soils, filter quickly into the subsoil, feeding the extensive and abundant Etna aquifer. In the event that the rains fall in areas characterized by the presence of soils with medium-low and low permeability, they are unable to infiltrate in the subsoil quickly and sometimes trigger superficial erosion phenomena or below the urban surface.

After defining the lithotypes that characterize the study area with the respective permeability parameters, and assessing the triggering cause of the subsidence phenomena, in order to identify and delimit both the areas subject to subsidence and the water outflow routes in the subsoil, three geoelectric field surveys were performed during the period 2015-2017. 
Through the surveys data elaboration, six 3D models have been reconstructed showing the resistivity distribution in the subsoil. The range of resistivity values identified are in agreement with the literature values (Palacky 1988; Glover 2015; Agustina et al. 2018) estimated for the lithotypes present at the site. Therefore, it is possible to state that there is an excellent correlation between geophysical and geological data.

The ERT 3D surveys allowed optimally define the resistivity distribution in the investigated subsoil. It was thus possible to identify humid areas subject to underground water circulation, characterized by low resistivity values (blue volumes), and areas characterized by the presence of possible cavities or non-compacted soils, which differ in their high resistivity values (red volumes).

\section{Conclusive remarks}

This multidisciplinary study, based on the analysis of rainfall, geological, hydrogeological and geophysical data, has allowed us to develop a methodological approach aimed at studying the subsidence phenomena that occur in a densely urbanized area under various aspects:

- The reconstruction of the lithological and permeability models, and the rainfall data analysis allowed to assess the soil piping triggering factor and correlate it to the site geological context. The geological and hydrogeological models have highlighted the presence of erodible soils, low permeable, and fractured rocks high permeable;

- The 3D ERT surveys have allowed to locate in the subsoil the areas affected by the instability as well as to identify further areas susceptible to instability phenomena;

- The analysis of rainfall intensity relative to all rainfall events occurred in the study area between January 2015 and February 2018 has highlight the threshold values that trigger the soil piping phenomena in the investigated site. In particular the rainfall events that give rise to such phenomena are chraracterized by rainfall intensity greater than $19 \mathrm{~mm} / \mathrm{h}$ and duration greater than $2 \mathrm{~h}$. However, the analysis also show that these phenomena can be triggered by rainfall events with minor intensity, but prolonged duration over time $(>27 \mathrm{~h})$.

It is clear that the physical vulnerability of the territory, subject to intense rainfall events and the erodibility of tuffites, in an urban context, such as that of Valverde municipality, involves a risk factor both for the infrastructures present, some of historical and artistic interest, and for the population. It cannot be excluded that the presence of the urban centre, build on a paleo-riverbed, significantly increases the vulnerability of the territory, triggering a series of complications that highlight a poor and sometimes absent land use planning.

Acknowledgements The authors are grateful to Dott. Geol. Michele Bongiovanni for providing useful information on the geology of the study area, and to Mr. Alfio Bonanno for allowing the use of the rainfall data of his weather station.

Author contributions Graziano Patti, Sabrina Grassi and Sebastiano Imposa contributed to the study conception and design. Material preparation, data collection and analysis were performed by Graziano Patti, Gabriele Morreale and Mauro Corrao. The first draft of the manuscript was written by Sabrina Grassi and Graziano Patti, all authors commented on previous versions of the manuscript. All authors read and approved the final manuscript.

Funding Open access funding provided by Università degli Studi di Catania within the CRUI-CARE Agreement. This work was supported by the Department of Biological, Geological and Environmental Sciences, 
University of Catania, in the frame of "Piano Triennale della Ricerca (2016-2018) linea di intervento 2" (Grant Number 22722132130), research scientific responsible Sebastiano Imposa.

\section{Declarations}

Conflict of interest The authors have no financial or proprietary interests in any material discussed in this article.

Open Access This article is licensed under a Creative Commons Attribution 4.0 International License, which permits use, sharing, adaptation, distribution and reproduction in any medium or format, as long as you give appropriate credit to the original author(s) and the source, provide a link to the Creative Commons licence, and indicate if changes were made. The images or other third party material in this article are included in the article's Creative Commons licence, unless indicated otherwise in a credit line to the material. If material is not included in the article's Creative Commons licence and your intended use is not permitted by statutory regulation or exceeds the permitted use, you will need to obtain permission directly from the copyright holder. To view a copy of this licence, visit http://creativecommons.org/licenses/by/4.0/.

\section{References}

Agustina RD, Pazha H, Sugilar H (2018) Identification of subsurface basement rock using geoelectrical resistivity method in development area (campus 2 UIN Sunan Gunung Djati Bandung). IOP Conf Ser Mater Sci Eng. https://doi.org/10.1088/1757-899X/434/1/012289

Archie GE (1942) The electrical resistivity log as an aid in determining some reservoir characteristics. Trans AIME 146(01):54-62

Barone G, Branca C, Gresta S, Imposa S, Leone A, Majolino D (2004) Geoarcheometric and geophysical methodologies applied to the study of cultural heritage:"St Agata la Vetere" in Catania (Sicily, Italy). J Cult Herit 5(3):263-271

Barreca G, Bonforte A, Neri M (2013) A pilot GIS database of active faults of Mt Etna (Sicily): A tool for integrated hazard evaluation. J Volcanol Geoth Res 251:170-186

Bernatek-Jakiel A, Kondracka M (2016) Combining geomorphological mapping and near surface geophysics (GPR and ERT) to study piping systems. Geomorphology 274:193-209

Bernatek-Jakiel A, Poesen J (2018) Subsurface erosion by soil piping: significance and research needs. Earth Sci Rev 185:1107-1128

Bigg GR (1991) Kriging and intraregional rainfall variability in England. Int J Climatol 11(6):663-675

Bing Z, Greenhalgh SA (2001) Finite element three-dimensional direct current resistivity modelling: accuracy and efficiency considerations. Geophys J Int 145(3):679-688

Boucher SC (1995) Management options for acidic sodic soil affected by tunnel erosion. In: Naidu R, Sumner ME, Rengasamy P (eds) Australian sodic soils: distribution, properties and management, pp 239-246

Bovi RC, Moreira CA, Rosolen VS, Rosa FTG, Furlan LM, Helene LPI (2020) Piping process: genesis and network characterization through a pedological and geophysical approach. Geoderma 361:114101

Branca S, Coltelli M, Groppelli G, Lentini F (2011) Geological map of Etna volcano, 1: 50,000 scale. Ital J Geosci 130(3):265-291

Caccamo MT, Castorina G, Colombo F, Insinga V, Maiorana E, Magazù S (2017) Weather forecast performances for complex orographic areas: Impact of different grid resolutions and of geographic data on heavy rainfall event simulations in Sicily. Atmos Res 198:22-33

Carollo A, Capizzi P, Martorana R (2020) Joint interpretation of seismic refraction tomography and electrical resistivity tomography by cluster analysis to detect buried cavities. J Appl Geophy 178:104069

Coco G, Corrao M (2009) Geofisica applicata. Palermo, Italy, pp 198-226

Constable SC, Parker RL, Constable CG (1987) Occam's inversion: a practical algorithm for generating smooth models from electromagnetic sounding data. Geophysics 52(3):289-300

Cosentino PL, Martorana R, Terranova LM (1999) The resistivity grid to optimize tomographic 3D imaging. In: 5th EEGS-ES Meeting (pp cp-35) European Association of Geoscientists \& Engineers

Costantini EA, Fantappié ML'Abate G (2013) Climate and pedoclimate of Italy. In: The soils of Italy. Springer, Dordrecht 19-37

Cressie N (1990) The origins of kriging. Math Geol 22(3):239-252 
De Groot-Hedlin C, Constable S (1990) Occam's inversion to generate smooth, two-dimensional models from magnetotelluric data. Geophysics 55(12):1613-1624

Ferrara V (1975) Idrogeologia del versante orientale dell'Etna. Atti $3^{\circ}$ Conv Int sulle Acque Sotterranee 91-144. Palermo

Ferrara V (2010) Le acque termominerali di S. Venera al Pozzo Studi e indagini idrogeologiche. Mem Rend Acc Degli Zelanti e Dei Dafnici 9:25-41

Ferrara V, Pappalardo G (2008) The hydrogeological map of the Etna volcanic massif as useful tool for groundwater resource management. Ital J Eng Geol Environ 1:77-89

Ferrara V, Barbagallo M, Maugeri S (2001) Carta idrogeologica del massiccio vulcanico dell'Etna. C.N.R. - GNDCI, S.EL.CA., Firenze

Giampaolo V, Capozzoli L, Grimaldi S, Rizzo E (2016) Sinkhole risk assessment by ERT: The case study of Sirino Lake (Basilicata, Italy). Geomorphology 253:1-9

Glover PWJ (2015) Geophysical properties of the near surface earth: electrical properties. Treatise on geophysics, pp 89-137

Griffiths DH, Barker RD (1993) Two-dimensional resistivity imaging and modelling in areas of complex geology. J Appl Geophys 29(3-4):211-226

Imposa S, Barone G, Coco G, Corrao M, Dell'Ali P, Puglia A, Nicotra A, Vinci S (2004) Ground penetrating radar and electrical survey of the Roman "Terme Achilliane" in Catania (Sicily): a case history. Contrib Geophy Geod 34(4):387-403

Imposa S, Barone F, Chiavetta F, Coco G, Corrao M, Chisari D (2007) A preliminary study of the subsoil of the Roman Amphitheatre of Catania (Sicily) through integrated geophysical and stratigraphic data. Il Nuovo Cimento C 30(6):577-586

Intrieri E, Gigli G, Nocentini M, Lombardi L, Mugnai F, Fidolini F, Casagli N (2015) Sinkhole monitoring and early warning: An experimental and successful GB-InSAR application. Geomorphology 241:304-314

Kaufmann G (2014) Geophysical mapping of solution and collapse sinkholes. J Appl Geophys 111:271-288

Keller GV, Rapolla A (1974) Electrical prospecting methods in volcanic and geothermal environments. Dev Solid Earth Geophy Elsevier 6:133-166

Krawczyk CM, Polom U, Trabs S, Dahm T (2012) Sinkholes in the city of Hamburg-New urban shearwave reflection seismic system enables high-resolution imaging of subrosion structures. J Appl Geophys 78:133-143

Kumar Adhikary S, Muttil N, Gokhan Yilmaz A (2016) Ordinary kriging and genetic programming for spatial estimation of rainfall in the Middle Yarra River catchment Australia. Hydrol Res 47(6):1182-1197

Lee EJ, Shin SY, Ko BC, Chang C (2016) Early sinkhole detection using a drone-based thermal camera and image processing. Infrared Phys Technol 78:223-232

Loke MH, Barker RD (1996) Rapid least-squares inversion of apparent resistivity pseudosections by a quasi-Newton method 1. Geophys Prospect 44(1):131-152

Martinotti ME, Pisano L, Marchesini I, Rossi M, Peruccacci S, Brunetti MT, Melillo M, Amoruso G, Loiacono P, Vennari C, Vessia G, Trabace M, Parise M, Guzzetti F (2017) Landslides, floods and sinkholes in a karst environment: the 1-6 September 2014 Gargano event, southern Italy. Nat Hazard 17(3):467-480

Martorana R, Fiandaca G, Casas Ponsati A, Cosentino PL (2009) Comparative tests on different multielectrode arrays using models in near-surface geophysics. J Geophys Eng 6(1):1-20

Martorana R, Capizzi P, D’Alessandro A, Luzio D (2017) Comparison of different sets of array configurations for multichannel 2D ERT acquisition. J Appl Geophys 137:34-48

Millán-Vega H, Rabelo-Lima J, Valderá-Figueredo N (2020) Spatial structure of precipitation in the brazilian amazonia: geostatistics with block kriging. Revista Cubana de Meteorología 26(4)

Palacky GJ (1988) Resistivity characteristics of geologic targets. Electromagn Methods App Geophy 1:53-129

Pappalardo G, Imposa S, Barbano MS, Grassi S, Mineo S (2018) Study of landslides at the archaeological site of Abakainon necropolis (NE Sicily) by geomorphological and geophysical investigations. Landslides 15(7):1279-1297

Pazzi V, Tapete D, Cappuccini L, Fanti R (2016) An electric and electromagnetic geophysical approach for subsurface investigation of anthropogenic mounds in an urban environment. Geomorphology 273:335-347

Pazzi V, Di Filippo M, Di Nezza M, Carlà T, Bardi F, Marini F, Fontanelli K, Intrieri E, Fanti R (2018) Integrated geophysical survey in a sinkhole-prone area: Microgravity electrical resistivity tomographies and seismic noise measurements to delimit its extension. Eng Geol 243:282-293 
Pellicone G, Caloiero T, Modica G, Guagliardi I (2018) Application of several spatial interpolation techniques to monthly rainfall data in the Calabria region (southern Italy). Int J Climatol 38(9):3651-3666

Pereyra MA, Fernández DS, Marcial ER, Puchulu ME (2020) Agricultural land degradation by piping erosion in Chaco Plain, Northwestern Argentina. Catena 185:104295

Poulidis AP, Takemi T (2017) A 1998-2013 climatology of Kyushu, Japan: seasonal variations of stability and rainfall. Int J Climatol 37(4):1843-1858

Raffaele M, Caccamo M T, Castorina G, Munaò G, Magazù S (2020) A didactic approach to the Machine Learning application to weather forecast. arXiv preprint aiv:200616162

Romano R, Sturiale C, Lentini F (1979) Geological map of Mt Etna. CNR Progetto Finalizzato Geodinamica Istituto Internazionale Di Vulcanologia Catania 1(50):000

Samyn K, Mathieu F, Bitri A, Nachbaur A, Closset L (2014) Integrated geophysical approach in assessing karst presence and sinkhole susceptibility along flood-protection dykes of the Loire River Orléans France. Eng Geol 183:170-184

Santarato G, Ranieri G, Occhi M, Morelli G, Fischanger F, Gualerzi D (2011) Three-dimensional electrical resistivity tomography to control the injection of expanding resins for the treatment and stabilization of foundation soils. Eng Geol 119(1-2):18-30

Sasaki Y (1992) Resolution of resistivity tomography inferred from numerical simulation 1. Geophys Prospect 40(4):453-463

Sevil J, Gutiérrez F, Zarroca M, Desir G, Carbonel D, Guerrero J, Linares R, Roqué C, Fabregat I (2017) Sinkhole investigation in an urban area by trenching in combination with GPR ERT and high-precision leveling Mantled evaporite karst of Zaragoza city NE Spain. Eng Geol 231:9-20

Regione Siciliana - SIAS - Servizio Informativo Agrometeorologico Siciliano

Smith DL (1986) Application of the pole-dipole resistivity technique to the detection of solution cavities beneath highways. Geophysics 51(3):833-837

Tong LT, Yang CH (1990) Incorporation of topography into two-dimensional resistivity inversion. Geophysics 55(3):354-361

Toulkeridis T, Rodríguez F, Arias Jiménez N, Baile DS, Martínez RS, Addison A, Carreòn Freyre D, Mato F, Díaz Perez C (2016) Causes and consequences of the sinkhole at El Trébol of Quito, Ecuador-implications for economic damage and risk assessment. Nat Hazard 16(9):2031-2041

Vannoppen W, Verachtert E, Poesen J (2017) Pipeflow response in loess-derived soils to precipitation and groundwater table fluctuations in a temperate humid climate. Hydrol Process 31(3):586-596

Viero A, Galgaro A, Morelli G, Breda A, Francese RG (2015) Investigations on the structural setting of a landslide-prone slope by means of three-dimensional electrical resistivity tomography. Nat Hazards 78(2):1369-1385

Waltham T, Waltham AC, Bell FG, Culshaw MG (2005) Sinkholes and subsidence: karst and cavernous rocks in engineering and construction. Springer Science \& Business Media

Wilson GV, Wells R, Kuhnle R, Fox G, Nieber J (2018) Sediment detachment and transport processes associated with internal erosion of soil pipes. Earth Surf Proc Land 43(1):45-63

Wu X, Wei Y, Cai C, Yuan Z, Liao Y, Li D (2020) Effects of erosion-induced land degradation on effective sediment size characteristics in sheet erosion. CATENA 195:104843

Yano A, Shinohara Y, Tsunetaka H, Mizuno H, Kubota T (2019) Distribution of landslides caused by heavy rainfall events and an earthquake in northern Aso Volcano, Japan from 1955 to 2016. Geomorphology 327:533-541

Zeng RQ, Meng XM, Zhang FY, Wang SY, Cui ZJ, Zhang MS, Zhang Y, Chen G (2016) Characterizing hydrological processes on loess slopes using electrical resistivity tomography-A case study of the Heifangtai Terrace Northwest China. J Hydrol 541:742-753

Zhou W, Beck BF, Adams AL (2002) Effective electrode array in mapping karst hazards in electrical resistivity tomography. Environ Geol 42(8):922-928

Publisher's Note Springer Nature remains neutral with regard to jurisdictional claims in published maps and institutional affiliations. 